NBER WORKING PAPER SERIES

\title{
THE EFFECT OF FINANCIAL DEVELOPMENT ON CONVERGENCE: THEORY AND EVIDENCE
}

\author{
Philippe Aghion \\ Peter Howitt \\ David Mayer-Foulkes \\ Working Paper 10358 \\ http://www.nber.org/papers/w10358
NATIONAL BUREAU OF ECONOMIC RESEARCH
1050 Massachusetts Avenue
Cambridge, MA 02138
March 2004

With the usual caveat we thank Daron Acemoglu, Sean Campbell, Sebnem Kalemli-Ozcan, Andrei Shleifer, David Weil, and participants at the 2003 NBER Summer Institute, McMaster University, the 2003 Canadian Macroeconomics Study Group and the Federal Reserve Board for helpful comments. Cristina Santos and Stylianos Michalopoulos provided excellent research assistance. The views expressed herein are those of the authors and not necessarily those of the National Bureau of Economic Research.

(C)2004 by Philippe Aghion, Peter Howitt, and David Mayer-Foulkes. All rights reserved. Short sections of text, not to exceed two paragraphs, may be quoted without explicit permission provided that full credit, including $(\mathrm{C}$ notice, is given to the source. 
The Effect of Financial Development on Convergence: Theory and Evidence

Philippe Aghion, Peter Howitt, and David Mayer-Foulkes

NBER Working Paper No. 10358

March 2004

JEL No. N1

\section{ABSTRACT}

We introduce imperfect creditor protection in a multi-country version of Schumpeterian growth theory with technology transfer. The theory predicts that the growth rate of any country with more than some critical level of financial development will converge to the growth rate of the world technology frontier, and that all other countries will have a strictly lower long-run growth rate. The theory also predicts that in a country that converges to the frontier growth rate, financial development has a positive but eventually vanishing effect on steady-state per-capita GDP relative to the frontier. We present cross-country evidence supporting these two implications. In particular, we find a significant and sizeable effect of an interaction term between initial per-capita GDP (relative to the United States) and a financial intermediation measure in an otherwise standard growth regression, implying that the likelihood of converging to the U.S. growth rate increases with financial development. We also find that, as predicted by the theory, the direct effect of financial intermediation in this regression is not significantly different from zero. These findings are robust to alternative conditioning sets, estimation procedures and measures of financial development.

Philippe Aghion
Department of Economics
Harvard University
Cambridge, MA 02138
and NBER
p_aghion@harvard.edu

Peter Howitt

Department of Economics

Brown University

Box B

Providence, RI 02912-0001

and NBER

peter_howitt@brown.edu
David Mayer-Foulkes

Division de Economia

CIDE

Carretera Mexico Toluca

3655

01210 Mexico, D.F.

Mexico

david.mayer@cide.edu 


\section{Introduction}

Most current theories of the cross-country distribution of per-capita income imply that all countries share the same long-run growth rate (of TFP or per-capita GDP). Yet the historical record shows that growth rates can differ substantially across countries for long periods of time. For example, Pritchett (1997) estimates that the proportional gap in percapita GDP between the richest and poorest countries grew more than five-fold from 1870 to 1990, and according to the tables in Maddison (2001) the proportional gap between the richest group of countries and the poorest ${ }^{1}$ grew from 3 in 1820 to 19 in 1998.

The "great divergence" between rich and poor countries continued through the end of the twentieth century. Although many studies ${ }^{2}$ show that a large group of rich and middleincome countries have been converging to parallel growth paths over the past 50 years or so, the gap between these countries as a whole and the very poorest countries as a whole has continued to widen. For example, the proportional gap in per-capita GDP between MayerFoulkes's (2002) richest and poorest convergence groups grew by a factor of 2.6 between 1960 and 1995, and the proportional gap between Maddison's richest and poorest groups grew by a factor of 1.75 between 1950 and 1998 .

Technology appears to be the central factor underlying divergence. Easterly and Levine (2001) estimate that about $60 \%$ of the cross-country variation in growth rates of per-capita GDP is attributable to differences in productivity growth, while Klenow and RodríguezClare (1997) estimate that in their sample about $90 \%$ of the variation is attributable to differences in productivity growth. Feyrer (2001) finds that although the distribution of capital-output ratios is single-peaked, and the distribution of education levels is almost flat, the distribution of the productivity residual has become increasingly twin-peaked. Although the level of productivity can be affected by many factors other than technology, such as geography and institutions that affect the efficiency of resource allocation, it is hard to see how substantial differences in the growth rate of productivity persisting for such long periods of time can be accounted for by these other factors, which are themselves highly persistent over time. Instead it seems more likely that divergence reflects long-lasting cross-country differences in rates of technological progress.

These facts are especially puzzling when one takes into account the possibility of international technology transfer and the "advantage of backwardness" (Gerschenkron 1952) that it confers on technological laggards. That is, the further a country falls behind the world's technology leaders the easier it is for that country to progress technologically simply by implementing new technologies that have been discovered elsewhere. Eventually this advantage should be enough to stabilize the proportional gap that separates it from the leaders. This is what happens in neoclassical models that assume technology transfer is instantaneous (Mankiw, Romer and Weil, 1992), and even in models where technologies developed on the frontier are not "appropriate" for poorer countries (Basu and Weil, 1998; Acemoglu and Zilibotti, 2001), in models where technology transfer can be blocked by special interests (Parente and Prescott, 1994, 1999) and in models where a country adopts

\footnotetext{
${ }^{1}$ The richest group was Western Europe in 1820 and the "European Offshoots" (Australia, Canada, New Zealand and the United States) in 1998. The poorest group was Africa in both years.

${ }^{2}$ For example, Barro and Sala-i-Martin (1992), Mankiw, Romer and Weil (1992) and Evans (1996).
} 
institutions that impede technology transfer (Acemoglu, Aghion and Zilibotti, 2002). ${ }^{3}$

This paper explores the hypothesis that financial constraints prevent poor countries from taking full advantage of technology transfer and that this is what causes some of them to diverge from the growth rate of the world frontier. It introduces credit constraints into a multi-country version of Schumpeterian growth theory with technology transfer, ${ }^{4}$ and shows that the model implies a form of club convergence consistent with the broad facts outlined above. In the theory, countries above some threshold level of financial development will all converge to the same long-run growth rate (but not generally to the same level of per-capita GDP) and those below that threshold will have strictly lower long-run growth rates.

There are three key components to the theory. The first starts with the recognition that technology transfer is costly. The receiving country cannot just take foreign technologies off the shelf and implement them costlessly. Instead, the country must make technology investments of its own to master foreign technologies and adapt them to the local environment, because technological knowledge is often tacit and circumstantially specific. ${ }^{5}$ Although these investments may not involve scientists and high tech labs, and hence would not fit the conventional definition of $R \& D$, nevertheless they play much the same role as $R \& D$ in an innovation-based growth model. That is, they generate new technological possibilities in the country where they are conducted, building on knowledge that was created previously elsewhere. As Cohen and Levinthal (1989) and Griffith, Redding and Van Reenen (2001) have argued, each act of technology transfer requires an innovation on the part of the receiving country, and thus $\mathrm{R} \& \mathrm{D}$ or more generally technology investment is a necessary input to the process of technology transfer. Accordingly our theory assigns to R\&D the role that Nelson and Phelps (1966) assumed was played by human capital, namely that of determining a country's "absorptive capacity". ${ }^{6}$

The second key component is the assumption that as the global technology frontier advances, the size of investment required just in order to keep innovating at the same pace as before rises in proportion. This assumption recognizes the force of increasing complexity, which makes technologies increasingly difficult to master and to adapt to local circumstances. A similar assumption has been shown elsewhere to be helpful in accounting for the fact that productivity growth rates have remained stable in OECD countries over the second half of the 20th Century despite the steady increase in R\&D expenditures. ${ }^{7}$

The third key component is an agency problem that limits an innovator's access to external finance. Specifically we assume that an innovator can defraud her creditors by hiding the results of a successful innovation, at a cost that depends positively on the level

\footnotetext{
${ }^{3}$ Other theories of endogenous growth (for example Lucas, 1988) generate different long-run growth rates for different countries but only by ignoring the possibility of technology transfer.

${ }^{4}$ See Aghion and Howitt (1998), Howitt (2000), Acemoglu, Aghion and Zilibotti (2002), and Howitt and Mayer-Foulkes (2002). The last of these papers implies three convergence groups, analogous to the three groups of the present paper, but the disadvantage of backwardness that prevents some countries from converging in that paper arises from low levels of human capital rather than from credit-market imperfections.

${ }^{5}$ See Arrow (1969) and Evenson and Westphal (1995).

${ }^{6}$ To the extent that R\&D is human-capital intensive our theory can be seen as an elaboration of Nelson and Phelps. Grossman and Helpman (1991) and Barro and Sala-i-Martin (1997) also model technology transfer as taking place through a costly investment process, which they portray as imitation; but in these models technology transfer always leads to convergence in growth rates except in special cases studied by Grossman and Helpman where technology transfer is inactive in a steady state.

${ }^{7}$ See Jones (1995) and Howitt (1999).
} 
of financial development. Because of this, in equilibrium the innovator's access to external finance will be limited to some multiple of her own wage income, as in the theory of Bernanke and Gertler (1989) modified by Aghion, Banerjee and Piketty (1999). Since wages are limited by domestic productivity, therefore a technological laggard can face a disadvantage of backwardness that counteracts Gerschenkron's advantage; that is, the further behind the frontier it falls the less its innovators will be able to invest relative to what is required in order to keep innovating at a given rate. The lower the level of financial development in the country the lower will be the (private) cost of fraud, hence the lower will be the credit multiplier and the larger will be the associated disadvantage of backwardness. This is why in our theory the likelihood that a country will converge to the frontier growth rate is an increasing function of its level of financial development.

Our paper relates to several important strands of theory relating growth, convergence and financial market development. There is first the literature on poverty traps and interpersonal convergence or divergence in economies with credit market imperfections, in particular, Banerjee and Newman (1993), Galor and Zeira (1993), Aghion and Bolton (1997) and Piketty (1997). In these models ${ }^{8}$, all agents face the same production technology and, unlike in our model, the same (productivity-adjusted) investment $\operatorname{costs}^{9}$, and what generates poverty traps are either non-convexities in production or monitoring, or pecuniary externalities working through factor prices. However, there is no technical progress and therefore no positive long-run growth in these models, which therefore cannot analyze the issue of long term convergence in growth rates. A second strand analyzes the effects of financial constraints and/or financial intermediation on long-term growth. Thus, Greenwood and Jovanovic (1990), Levine (1991), Bencivenga and Smith (1991, 1993), Saint-Paul (1992), Sussman (1993), Harrison, Sussman and Zeira (1999) and Kahn (2001) analyze the effects of financial intermediation on growth in an AK-style model with no distinction being made between investing in technology and investing in physical or human capital accumulation. Whereas King and Levine (1993), de la Fuente and Marin (1996), Galetovic (1996), Blackburn and Hung (1998) and Morales (2003) consider the relationship between finance and growth in the context of innovation-based growth models. De Gregorio (1996) studies the effects on growth of financial constraints that inhibit human capital accumulation. Krebs (2003) shows how imperfect sharing of individual human-capital risk can depress long-run growth. However, none of these models analyzes the process of technology transfer that we are focusing on, and therefore none of them is capable of addressing the question of why technology transfer is not sufficient to put all countries on parallel long-run growth paths. Our question is not just why financial constraints make some countries poor but rather why financial constraints inhibit technological transfer and thus lead to an ever-increasing technology gap.

The paper also produces evidence to support its main implications. There is already a substantial body of evidence ${ }^{10}$ to the effect that financial development is an important determinant of a country's short-run growth rate, almost all of which is predicated on the

\footnotetext{
${ }^{8}$ See Banerjee (2003) for a comprehensive survey of this literature.

${ }^{9}$ In contrast, in our model countries face a productivity-adjusted cost of innovation which increases with its distance to the technological frontier. It is this the interplay between credit constraints and this technological heterogeneity which generates the possibility of long-term divergence.

${ }^{10}$ See the surveys by Levine $(1997,2003)$, and the book by Demirgüç-Kunt and Levine (2001).
} 
assumption of long-run convergence in growth rates. We extend this analysis to allow for the possibility of different long-run growth rates, using a cross section of 71 countries over the period 1960-1995. Specifically, we estimate the effect of an interaction term between initial per-capita GDP (relative to the United States) and financial development in an otherwise standard cross-country growth regression. We interpret a negative coefficient as evidence that low financial development makes convergence less likely. Using a measure of financial development first introduced by Levine, Loayza and Beck (2000) we find that the coefficient is indeed negative, and is large both statistically and economically.

Our empirical methodology is similar to that of Benhabib and Spiegel (2002), who found a negative interaction term between initial TFP and schooling and concluded that schooling was a key determinant of whether or not a country will converge to the frontier growth rate. We test the robustness of our results by including both schooling and an interaction term between the initial GDP gap and schooling as additional regressors in our equation. In addition, we repeat this robustness test using instead of schooling 30 different variables suggested by other growth theories. In all cases the main implications of our theory pass the test. We also present evidence to the effect that the main channel through which financial development affects convergence is productivity growth, as implied by the theory, rather than capital accumulation, and show that our results are robust to elimination of outliers, to alternative conditioning sets, to alternative estimation procedures and to alternative measures of financial development.

\section{Theoretical framework}

We follow Acemoglu, Aghion and Zilibotti (2002) in casting Schumpeterian growth theory in a simple discrete-time framework. There are $m$ countries, who do not exchange goods or factors, but do make use of each others' technological ideas. There is a continuum of individuals in each country. Each country has a fixed population $L$, which for notational convenience we normalize to unity. Thus aggregate and per-capita quantities are identical. Everyone lives for two periods, being endowed with two units of labor services in the first period and none in the second, with a utility function linear in consumption: $U=c_{1}+\beta c_{2}$, with $0<\beta<1$. Within each country the growth path is determined as follows.

\subsection{The general sector}

There is one multi-purpose "general" good, produced by labor and a continuum of specialized intermediate goods according to the production function:

$$
Z_{t}=L^{1-\alpha} \int_{0}^{1} A_{t}(i)^{1-\alpha} x_{t}(i)^{\alpha} d i, \quad 0<\alpha<1
$$

where $x_{t}(i)$ is the input of the latest version of intermediate good $i$ and $A_{t}(i)$ is the productivity parameter associated with it. The general good is used for consumption, as an input to R\&D and also as an input to the production of intermediate goods.

The general good is produced under perfect competition, so the price of each interme- 
diate good equals its marginal product:

$$
p_{t}(i)=\alpha\left(\frac{x_{t}(i)}{A_{t}(i)}\right)^{\alpha-1} .
$$

(We use the general good as numéraire, and $L=1$ ).

\section{$2.2 \quad$ Intermediate sectors}

For each intermediate good $i$ there is one person born each period $t-1$ who is capable of producing an innovation for the next period. This person is called the $i^{\text {th }}$ innovator in $t-1$, and if she succeeds (innovates) then she will be the $i^{t h}$ incumbent in $t$. Let $\mu_{t}(i)$ be the probability that she succeeds. Then:

$$
A_{t}(i)=\left\{\begin{array}{cc}
\bar{A}_{t} & \text { with probability } \mu_{t}(i) \\
A_{t-1}(i) & \text { with probability } 1-\mu_{t}(i)
\end{array}\right\}
$$

where $\bar{A}_{t}$ is the world technology frontier, which grows at the constant rate $g$, taken as given for now. The fact that a successful innovator gets to implement $\bar{A}_{t}$ is a manifestation of technology transfer, of the kind that Keller (2002) calls "active"; that is, domestic R\&D makes use of ideas developed elsewhere in the world. ${ }^{11}$

In each intermediate sector where an innovation has just occurred, the incumbent is able to produce any amount of the intermediate good using as the sole input one unit of the general good per unit of intermediate good. In addition, in every intermediate sector there is an unlimited number of people capable of producing copies of the latest generation of that intermediate good at a unit cost of $\chi>1$.

So in sectors where an innovation has just occurred, the incumbent will be the sole producer, at a price equal to the unit cost of the competitive fringe, ${ }^{12}$ whereas in noninnovating sectors where the most recent incumbent is dead, production will take place under perfect competition with a price equal to the unit cost of each producer. In either event the price will be $\chi$, and according to the demand function (2) the quantity demanded will be:

$$
x_{t}(i)=(\alpha / \chi)^{\frac{1}{1-\alpha}} A_{t}(i) .
$$

It follows that an unsuccessful innovator will earn zero profits next period, whereas the profit of an incumbent will be $\pi_{t}(i)=\pi \bar{A}_{t}$, where $\pi=(\chi-1)(\alpha / \chi)^{\frac{1}{1-\alpha}}$.

\subsection{Aggregate behavior}

Define the country's "average productivity" $A_{t}$ as:

$$
A_{t}=\int_{0}^{1} A_{t}(i) d i
$$

\footnotetext{
${ }^{11}$ In Appendix A we explore the more general case in which innovations do not result in an immediate jump to the frontier, so that:

$$
A_{t}(i)=\left\{\begin{array}{cc}
b \bar{A}_{t}+(1-b) A_{t-1} & \text { with probability } \mu_{t}(i) \\
A_{t-1}(i) & \text { with probability } 1-\mu_{t}(i)
\end{array}\right\}
$$

where $A_{t}$ is the average domestic productivity at date $t$ and $b$ is a real number between 0 and 1 .

${ }^{12}$ This requires the further assumption that $\chi<\alpha^{-\alpha}$, which we now make.
} 
Substituting (3) into (1) we see that gross output of the general good will be:

$$
Z_{t}=\zeta A_{t}
$$

where $\zeta=(\alpha / \chi)^{\frac{\alpha}{1-\alpha}}$.

In equilibrium the probability of innovation will be the same in each sector: $\mu_{t}(i)=\mu_{t}$ for all $i$; therefore average productivity evolves according to:

$$
A_{t}=\mu_{t} \bar{A}_{t}+\left(1-\mu_{t}\right) A_{t-1} .
$$

That is, the productivity parameter will equal $\bar{A}_{t}$ in the fraction $\mu_{t}$ of sectors that innovated at $t-1$, but will remain equal to $A_{t-1}(i)$ in the $1-\mu_{t}$ sectors that did not innovate at $t-1$, and since innovations are distributed randomly across sectors the average value of $A_{t-1}(i)$ among non-innovating sectors will equal the economy-wide average $A_{t-1}$.

Define the country's normalized productivity as:

$$
a_{t}=A_{t} / \bar{A}_{t}
$$

Normalized productivity is an inverse measure of the country's distance to the technological frontier, or its "technology gap". It follows that the gap evolves according to:

$$
a_{t}=\mu_{t}+\frac{\left(1-\mu_{t}\right)}{1+g} a_{t-1} \text {. }
$$

Since the general sector is perfectly competitive, the wage rate $w_{t}$ will be the marginal product of labor in producing the general good:

$$
w_{t}=(1-\alpha) Z_{t}=(1-\alpha) \zeta A_{t} .
$$

The fact that $w_{t}$ is proportional to domestic productivity $A_{t}$ plays an important role in what follows. For as we shall see it implies that technology investment in a country that is credit-constrained will be strictly proportional to $A_{t}$.

Value added in the general sector is wage income, whereas value added in the intermediate sectors is profit income. Per-capita income is the sum of value added in all sectors:

$$
Y_{t}=w_{t}+\mu_{t} \pi_{t}=(1-\alpha) \zeta A_{t}+\mu_{t} \pi \bar{A}_{t} .
$$

\subsection{Innovations}

In each sector the $R \& D$ investment needed to innovate at any given rate $\mu_{t}$ is governed by the cost function:

$$
N_{t-1}=\widetilde{n}\left(\mu_{t}\right) \bar{A}_{t}=\left(\eta \mu_{t}+\delta \mu_{t}^{2} / 2\right) \bar{A}_{t} \quad \eta, \delta>0
$$

where $N_{t-1}$ is the quantity of general good that must be invested. We multiply $\widetilde{n}$ by $\bar{A}_{t}$ to recognize the "fishing-out" effect; the further ahead the frontier moves the more difficult it is to innovate. This effect is crucial in what follows.

Assume also that:

$$
\eta<\beta \pi<\eta+\delta .
$$

This condition guarantees that the probability $\mu_{t}$ will always lie strictly between 0 and 1 .

In equilibrium $\mu_{t}$ will be chosen so as to maximize the expected net payoff:

$$
\beta \mu_{t} \pi \bar{A}_{t}-\tilde{n}\left(\mu_{t}\right) \bar{A}_{t}
$$

in each sector, subject to credit constraints. 


\subsection{Equilibrium innovation under perfect credit markets}

In this section we show that if innovators had unlimited access to outside finance all economies would converge to the same growth rate. The level of each country's growth path might be different because of country-specific differences in parameters such as $\beta$ and $\chi$, but the world distribution of income would exhibit parallel convergence.

Suppose accordingly that each innovator can borrow (from other young people) unlimited quantities at the going rate $r=\beta^{-1}-1$ subject to a binding commitment to repay. Then $\mu_{t}$ will be chosen so as to maximize (7) with no constraint. This implies that $\mu_{t}=\mu^{*}$, where:

$$
\widetilde{n}^{\prime}\left(\mu^{*}\right)=\beta \pi,
$$

that is:

$$
\mu^{*}=(\beta \pi-\eta) / \delta
$$

The equilibrium $R \& D$ expenditure will be:

$$
N_{t-1}^{*}=n^{*} \bar{A}_{t}
$$

where:

$$
n^{*}=\widetilde{n}\left(\mu^{*}\right)=\frac{\beta^{2} \pi^{2}-\eta^{2}}{2 \delta} .
$$

It follows from this and equation (4) that the country's technology gap evolves according to:

$$
a_{t+1}=\mu^{*}+\frac{\left(1-\mu^{*}\right)}{1+g} a_{t} \equiv F_{1}\left(a_{t}\right)
$$

which converges in the long run to the steady-state value:

$$
a^{*}=\frac{(1+g) \mu^{*}}{g+\mu^{*}} \in(0,1) .
$$

Per-capita income in the steady state is:

$$
Y_{t}^{*}=\left[(1-\alpha) \zeta a^{*}+\mu^{*} \pi\right] \bar{A}_{t}
$$

which grows at the same rate $g$ as the technology frontier $\bar{A}_{t}$, as claimed.

\subsection{Credit constraints}

Now suppose that credit markets are imperfect. Each innovator is a young person with access to the wage income $w_{t}$. Thus to invest $N_{t}$ in an $\mathrm{R} \& \mathrm{D}$ project she must borrow $L=N_{t}-w_{t}$. Following Aghion, Banerjee and Piketty (1999) suppose that at a cost $c N_{t}$ the innovator can hide the result of a successful innovation and thereby avoid repaying her creditors, where $0<c<1$. This cost as an indicator of the degree of creditor protection. In countries where laws and institutions make fraud a costly option creditors are better protected and therefore, as we shall see, credit is more readily available to entrepreneurs.

The innovator must pay the hiding cost at the beginning of the period, when she decides whether or not to be dishonest. She will do so when it is in her self interest, namely when the following incentive-compatibility constraint is violated:

$$
c N_{t} \geq \widetilde{\mu}\left(N_{t} / \bar{A}_{t+1}\right) R\left(N_{t}-w_{t}\right)
$$


where $R$ is the interest factor on the loan and $\widetilde{\mu}$ is the production function for innovations, i.e. the non-negative inverse of the function ${ }^{13} \widetilde{n}$ :

$$
\widetilde{\mu}(n)=\left(\sqrt{\eta^{2}+2 \delta n}-\eta\right) / \delta .
$$

The right hand side of (10) is the expected saving from deciding to be dishonest when investing at the rate $N_{t}$.

The only potential lenders in this OLG model are other young people, ${ }^{14}$ who will lend only if offered an expected rate of return equal to $r$. Thus the interest factor on the loan in equilibrium must satisfy not only the incentive-compatibility condition (10) but also the arbitrage condition:

$$
\widetilde{\mu}\left(N_{t} / \bar{A}_{t+1}\right) R=1+r
$$

so that the incentive-compatibility condition boils down to an upper limit on the entrepreneur's investment:

$$
N_{t} \leq \frac{1+r}{1+r-c} w_{t}
$$

This limit will be binding if the unconstrained optimal investment $n^{*} \bar{A}_{t+1}$ violates it. Substituting for the equilibrium wage using equation (5) we see that the credit limit will be binding at date $t$ if the country falls too far behind the technology frontier; that is, if its technology gap satisfies the inequality:

$$
a_{t}<n^{*} / \omega(c) \equiv \underline{a}(c)
$$

where:

$$
\omega(c) \equiv \frac{(1+r)(1-\alpha) \zeta}{(1+r-c)(1+g)} .
$$

Intuitively, entrepreneurs in a country that has fallen too far behind the frontier can no longer finance the investments needed to optimally invest in frontier technology. ${ }^{15}$

The function $\omega(c)$ is a (productivity-adjusted) "finance multiplier" which depends positively on the cost $c$ of defrauding a creditor. Therefore $\underline{a}(c)$ is a decreasing function of $c$. That is, in countries with a high degree of creditor protection the critical gap value $\underline{a}$ below which entrepreneurs become credit-constrained is lower than in countries with a low degree of creditor protection.

When (13) holds, each entrepreneur will spend the maximum possible on technology investment - - the amount that satisfies (12) with equality:

$$
N_{t}=\frac{1+r}{1+r-c} w_{t}=\omega(c) a_{t} \bar{A}_{t+1}
$$

\footnotetext{
${ }^{13}$ Note that $\widetilde{\mu}(0)=0, \widetilde{\mu}^{\prime}(n)>0$ and $\widetilde{\mu}^{\prime \prime}(n)<0$.

${ }^{14}$ If we assume that the discount factor $\beta$ is the same in all countries then lenders can come from any country. Credit market imperfections in this model do not imply international capital immobility because the risk of default is assumed to be independent of the lender's nationality.

${ }^{15}$ This raises the question of why a constrained entrepreneur at $t-1$ would not instead target a lower technology level $B_{t}<\bar{A}_{t}$, which would be less expensive given the assumption that the cost of innovating at a given rate is proportional to the targeted technology level. In Appendix B we answer the question by showing that this alternative would be dominated, from the entrepreneur's point of view, by the strategy of always targeting the frontier.
} 
resulting in the subsequent innovation rate $\mu_{t+1}=\widetilde{\mu}\left(\omega(c) a_{t}\right)$. Therefore $a_{t+1}$ will be determined according to:

$$
a_{t+1}=\widetilde{\mu}\left(\omega(c) a_{t}\right)+\frac{\left(1-\widetilde{\mu}\left(\omega(c) a_{t}\right)\right)}{1+g} a_{t} \equiv F_{2}\left(a_{t}\right)
$$

for as long as (13) holds.

\subsection{The world growth rate}

As in other Schumpeterian models, we suppose that the growth rate $g$ of the global technology frontier is determined by the pace of innovations in the leading countries, none of which are assumed to be credit constrained. For simplicity, assume there is just one leader, labeled country 1 . Then:

$$
g=\sigma \mu^{*}=\sigma \frac{\beta_{1} \pi_{1}-\eta_{1}}{\delta_{1}}
$$

where $\sigma>0$ is a spillover coefficient and the subscript 1 indicates a parameter value in country 1 .

\section{$3 \quad$ Theoretical predictions}

\subsection{Three dynamic patterns}

In general, the country's technology gap $a_{t}$ will evolve according to the unconstrained dynamical system (8) when $a_{t} \geq \underline{a}(c)$ and according to the constrained system (15) when $a_{t}<\underline{a}(c)$. Thus:

$$
a_{t+1}=F\left(a_{t}\right) \equiv \min \left\{F_{1}\left(a_{t}\right), F_{2}\left(a_{t}\right)\right\} .
$$

Note that $F_{1}$ is a linear function with positive vertical intercept and a slope between 0 and 1. Also, ${ }^{16} F_{2}$ is an increasing concave function when $a_{t} \leq \min \{\underline{a}(c), 1\}$, with $F_{2}(0)=0$ and:

$$
F_{2}^{\prime}(0)=\frac{\omega(c)}{\eta}+\frac{1}{1+g}
$$

We interpret countries where the cost $c$ of defrauding a creditor is higher as countries with more highly developed financial systems, because among the services performed by well functioning financial intermediaries and markets are the detection and prevention of fraud. Then countries will fall into three groups, defined by the value of their finance multiplier $\omega(c)$, which is an increasing function of our indicator $c$ of financial development. The evolution of the technology gap is illustrated for each case in Figures $1 \sim 3$ below.

1. Convergence in growth rate, no marginal effect of financial development.

When:

$$
\frac{n^{*}}{a^{*}} \leq \omega(c)
$$

then (since $\left.a^{*} \geq \underline{a}(c)\right) F\left(a^{*}\right)=F_{1}\left(a^{*}\right)$. As shown in Figure 1, $a_{t}$ will converge asymptotically to the unconstrained steady state $a^{*}>0$. Per-capita income will be

\footnotetext{
${ }^{16}$ See footnote 13 above.
} 
given by equation (9) in the long run, which implies that the country will grow at the same rate $g$ as the global technology frontier in the long run. Increases in financial development will have no marginal effect on either the steady-state growth rate or the steady-state technology gap; these converge respectively to the values $g$ and $a^{*}$ which are independent of $c$.

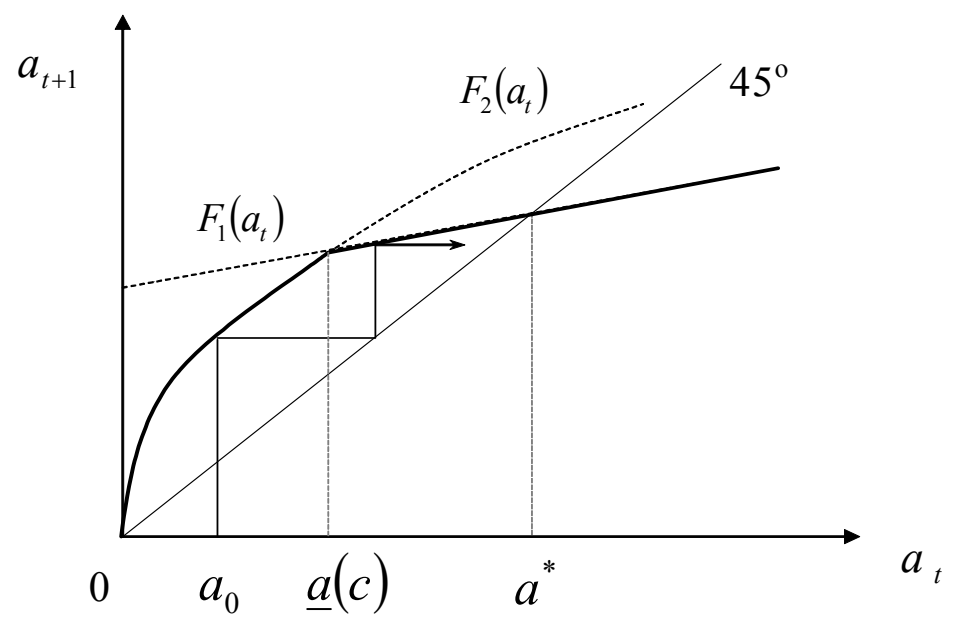

Figure 1: A country with the highest level of financial development

2. Convergence in growth rate with a level-effect of financial development.

When: ${ }^{17}$

$$
\frac{\eta g}{1+g} \leq \omega(c)<\frac{n^{*}}{a^{*}}
$$

then $F\left(a^{*}\right)<F_{1}\left(a^{*}\right)$, so $a_{t}$ cannot converge to the unconstrained steady state $a^{*}$. From (17) we have:

$$
F^{\prime}(0)=\frac{\omega(c)}{\eta}+\frac{1}{1+g} \geq \frac{g}{1+g}+\frac{1}{1+g}=1 .
$$

Therefore, as shown in Figure 2, $a_{t}$ will converge to a limit $\widehat{a}$ that is strictly positive (except in the borderline case where $\frac{\eta g}{1+g}=\omega(c)$ and $\widehat{a}=0$ ) but less than $a^{*}$. In the long run per, capita income will be:

$$
\widehat{Y}_{t}=[(1-\alpha) \zeta \widehat{a}+\widetilde{\mu}(\omega(c) \widehat{a}) \pi] \bar{A}_{t}<Y_{t}^{*}
$$

\footnotetext{
${ }^{17}$ Note that$$
\frac{\eta g}{1+g}<\frac{n^{*}}{a^{*}}
$$

because

$$
\frac{\frac{\eta g}{1+g}}{\frac{n^{*}}{a^{*}}}=\frac{\eta g \mu^{*}}{n^{*}\left(g+\mu^{*}\right)}<\frac{\eta \mu^{*}}{n^{*}}=\frac{\eta \mu^{*}}{\eta \mu^{*}+\delta\left(\mu^{*}\right)^{2} / 2}<1 .
$$
}


This country will also grow at the rate $g$ in the long run, because $\widehat{Y}_{t}$ is strictly proportional to $\bar{A}_{t}$, as is $Y_{t}^{*}$. Increases in financial development will have no marginal effect on the steady-state growth rate but they will have a positive marginal effect on the steady-state technology gap $\widehat{a}$, because they shift the curve $F_{2}\left(a_{t}\right)$ up in Figure $2 .{ }^{18}$ According to (18) increases in financial development will also have a positive effect on the country's steady-state per-capita GDP because of both the direct effect on $\widetilde{\mu}$ and the indirect effect on $\widehat{a}$.

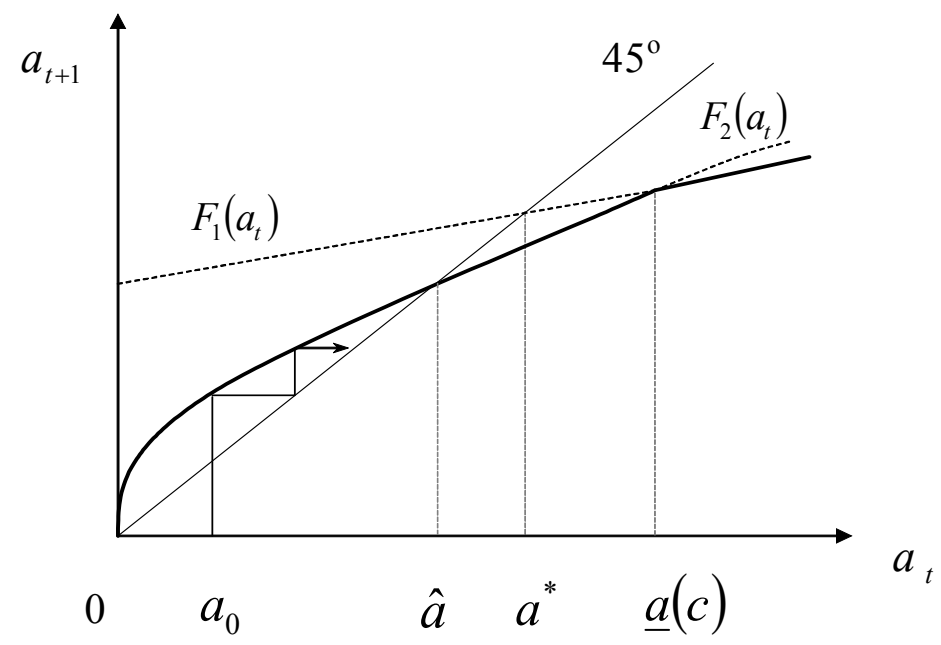

Figure 2: A medium level of financial development

3. Divergence in growth rate, with a growth-effect of financial development.

When:

$$
\omega(c)<\frac{\eta g}{1+g}
$$

then $F\left(a^{*}\right)<F_{1}\left(a^{*}\right)$ and $F^{\prime}(0)<1$, so $a_{t}$ will converge to zero, as shown in Figure 3. The following argument shows that in this case the rate of productivity growth, defined as $G_{t}=\left(A_{t+1} / A_{t}\right)-1$, will approach a limiting value that is strictly between 0 and $g$. By l'Hôpital's rule:

$$
\lim _{t \rightarrow \infty}\left(a_{t+1} / a_{t}\right)=\lim _{a \rightarrow 0} F^{\prime}(a)=\frac{\omega(c)}{\eta}+\frac{1}{1+g} \in(0,1) .
$$

Therefore:

$$
\lim _{t \rightarrow \infty} G_{t}=(1+g) \lim _{t \rightarrow \infty}\left(a_{t+1} / a_{t}\right)-1=(1+g) \frac{\omega(c)}{\eta} \in(0, g) .
$$

\footnotetext{
${ }^{18}$ Formally, from (15):
}

$$
\frac{\partial a_{t+1}}{\partial c}=\omega^{\prime}(c) a_{t} \widetilde{\mu}^{\prime}\left(\omega(c) a_{t}\right)\left(1-\frac{a_{t}}{1+g}\right)>0 .
$$


It can also be shown that in this case productivity and per-capita GDP have the same long-run growth rate. ${ }^{19}$ Thus the steady-state growth rate of per-capita GDP will be strictly less than the frontier growth rate $g$ and will be strictly increasing in the country's level of financial development.

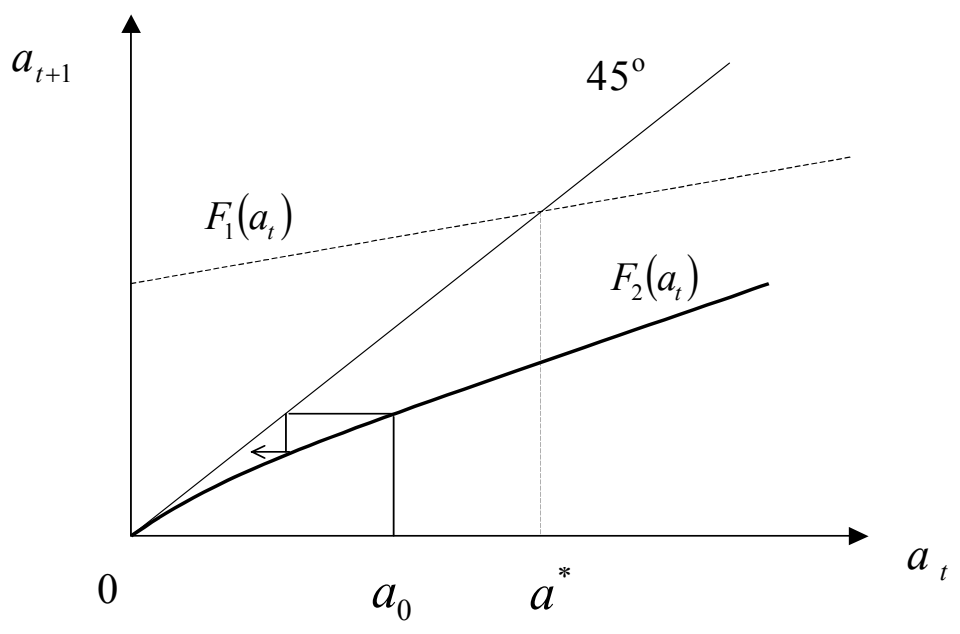

Figure 3: The lowest level of financial development

\subsection{Summary}

In summary, three central implications of our theory are that:

1. the likelihood that a country will converge to the frontier growth rate increases with its level of financial development,

\footnotetext{
${ }^{19}$ The long-run growth rates of productivity and per-capita GDP will be the same if $Y_{t} / A_{t}$ converges to a positive constant as $t \rightarrow \infty$. By (6) above:

$$
\frac{Y_{t}}{A_{t}}=(1-\alpha) \zeta+\pi \frac{\mu_{t}}{a_{t}}
$$

so we just need to show that

$$
\frac{a_{t}}{\mu_{t}}=\frac{a_{t}}{\widetilde{\mu}\left(\omega(c) a_{t-1}\right)}
$$

approaches a positive constant as $t \rightarrow \infty$. By (15) and the fact that $\lim _{t \rightarrow \infty} a_{t-1}=0$ :

$$
\lim _{t \rightarrow \infty} \frac{a_{t}}{\widetilde{\mu}\left(\omega(c) a_{t-1}\right)}=\lim _{a \rightarrow 0}\left\{1+\left(\frac{a}{\widetilde{\mu}(\omega(c) a)}-a\right) /(1+g)\right\} .
$$
}

By l'Hôpital's rule and the definition of $\widetilde{\mu}$ given in (11) above:

$$
\lim _{a \rightarrow 0} \frac{a}{\widetilde{\mu}(\omega(c) a)}=\frac{1}{\lim _{a \rightarrow 0} \frac{\partial}{\partial a} \widetilde{\mu}(\omega(c) a)}=\frac{\eta}{\omega(c)} .
$$

Therefore:

$$
\lim _{t \rightarrow \infty} \frac{a_{t}}{\mu_{t}}=1+\frac{\eta}{\omega(c)(1+g)}>0 . \|
$$


2. in a country that converges to the frontier growth rate, financial development has a positive but eventually vanishing effect on the steady-state level of per-capita GDP relative to the frontier, and

3. the steady-state growth rate of a country that fails to converge to the frontier growth rate increases with its level of financial development.

Actually, the above model implies a somewhat stronger version of $1 \sim 3$, namely that:

4. the effect of financial development on steady-state growth should be positive up to some critical level $F_{g}$ and zero thereafter, and the effect of financial development on the steady-state level of per-capita GDP should be positive up to some critical level $F_{y}$ and zero thereafter, with $F_{g}<F_{y}$.

The difference between 4 and the combination of $1 \sim 3$ is that 4 implies a zero effect on steady-state levels beyond some threshold, and that this threshold is greater than the growth threshold $F_{g}$.

In the next section we will confront these predictions with cross-country evidence on financial development and growth. Although the purpose of this exercise is certainly not to perform a structural estimation of our stylized model, in Appendix $\mathrm{C}$ we show that the empirical convergence equation (23) that we estimate below can be regarded as a smooth approximation to the theoretical difference equation (16) implied by the model.

\subsection{Empirical measures of financial intermediation}

We do not have a direct empirical measure of the exogenous cost $c$ of defrauding a creditor, which our theoretical analysis takes as an indicator of financial development. The empirical literature on finance and growth has used some measure of financial intermediary balance sheets relative to GDP as the indicator of financial development. This makes sense in the context of our model if we assume that all lending to entrepreneurs takes place through financial intermediaries and that all loans are paid (or written off) after one period.

Under these assumptions, the ratio of intermediary lending to GDP will be:

$$
F=\frac{N-w}{Y}
$$

where $N$ is $\mathrm{R} \& \mathrm{D}$ expenditure, so that $N-w$ is the amount of $\mathrm{R} \& \mathrm{D}$ expenditure that is financed through intermediaries. In a country where the finance constraint (12) is binding:

$$
F=\left(\frac{1+r}{1+r-c}-1\right) \frac{w}{Y}
$$

Given that wages constitute about 70 percent of per-capita GDP in most countries, this implies that:

$$
F \simeq \frac{0.7 \cdot c}{1+r-c}
$$

which is an increasing function of our theoretical measure $c$ of financial development. 
In countries where credit constraints are not binding, the theory implies that in steady state the $F$ ratio will be unrelated to our theoretical measure:

$$
F=\frac{n^{*}-(1-\alpha) \zeta a^{*}}{(1-\alpha) \zeta a^{*}+\mu^{*} \pi} .
$$

This makes $F$ endogenous to the growth process because variables such as $a^{*}$ and $\pi$ have effects on both $F$ and the level (or growth rate) of per-capita GDP. Therefore in our empirical work we will want to find instruments for $F$, preferably instruments whose primary impact on the growth process works through the laws and institutions that determine the extent of creditor rights in a country, and which are therefore closely related to the theoretical variable $c$. Our theory implies that implications $1 \sim 4$ above should hold when changes in financial development are measured by exogenous changes in $F$ attributable to such instruments.

\section{Credit and convergence: Evidence}

In this section we confront our theoretical predictions with evidence. After describing our data, we estimate some split-sample regressions as an introductory test for the coefficient changes that are expected across sub-samples. Then we carry out an interaction analysis aimed at testing implications 1 and 2 above. This interaction analysis provides strong evidence for our model and for the general proposition that a country's rate of convergence to the frontier growth rate depends on its level of financial development.

\subsection{Data}

In our empirical analysis we use cross-sectional data ${ }^{20}$ on 71 countries over the period 19601995, taken from Levine, Loayza and Beck (2000), who found a strongly positive and robust effect of financial intermediation on short-run growth in a regression with initial GDP on the right hand side. We use private credit as our measure of financial intermediation. This is the value of credits by financial intermediaries to the private sector, divided by GDP. It is the preferred measure of Levine, Loayza and Beck because it excludes credit granted to the public sector and credit granted by the central bank and development banks. We also report results below using alternative measures of financial intermediation.

Figures 4 and 5 show that the raw data are roughly consistent with the strong implication 4 stated in section 3.2. In Figure 4 the average growth rate of per-capita GDP for each country is plotted against the average level of financial intermediation. If we take out the outliers with the five highest growth rates, which are clearly countries with growth rates above their steady-state values, the scatter diagram appears consistent with a positive effect of financial intermediation on growth which vanishes once financial intermediation has reached a critical value $F_{g}$ approximately equal to the value achieved by Greece $(39 \%)$, as predicted by the first part of implication 4 . Figure 5 on the other hand plots the average log of per-capita GDP on the vertical axis. It appears consistent with a positive effect of financial intermediation on the level of GDP which vanishes once financial intermediation

\footnotetext{
${ }^{20}$ See Appendix D for description and sources of data.
} 
has reached a critical value $F_{y}$ approximately equal to the value achieved by Canada $(61 \%)$, as predicted by the second part of implication 4. Moreover, according to these rough estimates $F_{g}<F_{y}$, as predicted by the last part of implication 4 .

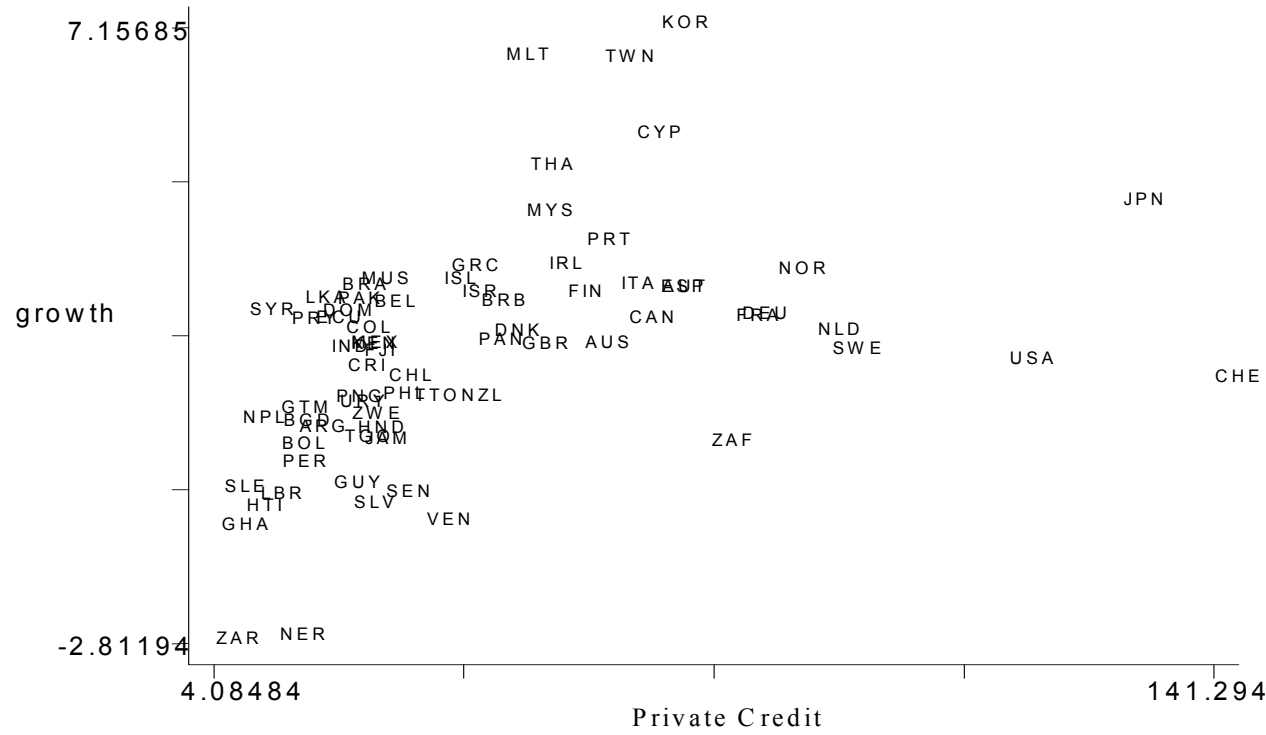

Figure 4: Financial intermediation and long-run growth of per-capita GDP

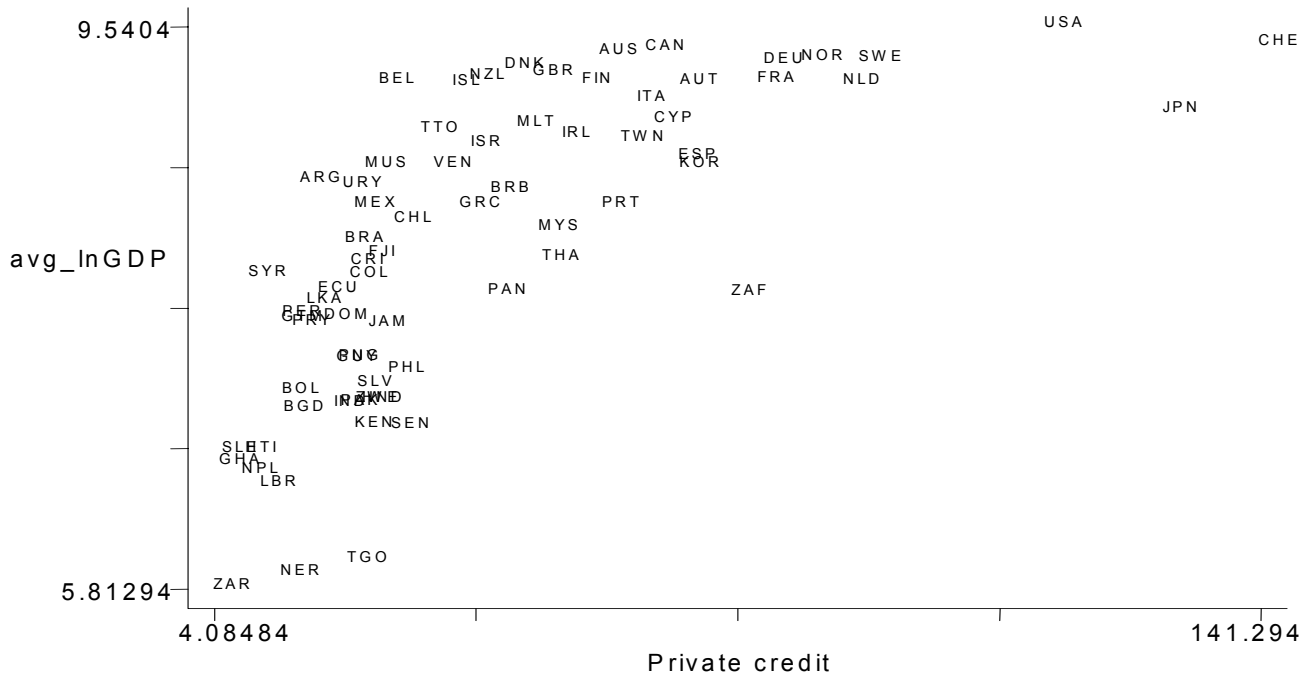

Figure 5: Financial intermediation and long-run average per-capita GDP

These figures do not control for the effects of initial GDP or any other possible influences on growth. Nor do they deal with the problem of possible endogeneity of financial intermediation. For these we turn to the following regression results. 


\subsection{Split-sample regressions}

A simple way to test implications $1 \sim 3$ above is to split the sample into different groups according to their level of financial intermediation and then to estimate the cross-country growth equation:

$$
g_{i}-g_{1}=\beta_{0}+\beta_{f} F_{i}+\beta_{y} \cdot\left(y_{i}-y_{1}\right)+\varepsilon_{i}
$$

within each group of countries. In (19), $g_{i}$ is the average growth rate of country $i$ 's percapita GDP over the 1960-95 period, $g_{1}$ is the frontier (US) growth rate (also of per-capita GDP) over that period, $F_{i}$ is the country's average level of financial intermediation, $y_{i}$ is the $\log$ of per-capita GDP in the country at the start of the period, $y_{1}$ is the log of per-capita GDP in the United States at the start of the period, $\beta_{0}, \beta_{f}$ and $\beta_{y}$ are constant coefficients and $\varepsilon_{i}$ a classical disturbance term.

The growth equation (19) is standard except for the presence of the U.S. variables $g_{1}$ and $y_{1}$. Since these variables are the same for all countries they just affect the constant term in a cross-section growth regression. We include them anyway to emphasize that the equation can be regarded as a difference equation in the "relative output" variable $\widehat{y}_{i}(t)$ defined as the log of per-capita GDP relative to the United States. That is, by definition the average growth rate differential $g_{i}-g_{1}$ equals the average change in $\widehat{y}_{i}(t)$ from the beginning of the sample period until the beginning of the next 35-year period, divided by 0.35 . So (19) relates the change in relative output to the level of relative output. There are two separate cases to consider:

1. Suppose $\beta_{y} \neq 0$. Then we can express (19) as the difference equation:

$$
\Delta y_{i}(t)=\lambda \cdot\left(\widehat{y}_{i}(t)-\widehat{y}_{i}^{*}\right)
$$

with the initial condition:

$$
\widehat{y}_{i}(0)=y_{i}-y_{1}
$$

where $\Delta$ is the forward difference operator, $\widehat{y}_{i}^{*}$ is the steady-state relative output:

$$
\widehat{y}_{i}^{*}=-\frac{\beta_{0}+\beta_{f} F_{i}+\varepsilon_{i}}{\beta_{y}}
$$

and:

$$
\lambda=(0.35) \cdot \beta_{y} .
$$

So in this case the coefficient $\beta_{y}$ is a convergence parameter determining whether or not, and if so how fast, the country's relative output converges to its steady-state value. More importantly for our purposes, $\beta_{y}$ also determines whether or not the country's growth rate converges to that of the United States, because (20) makes the growth rate differential proportional to relative output and thus implies that the growth rate differential will converge to zero if and only if relative output converges. A necessary condition for convergence is that $\beta_{y}<0$. If $\beta_{y}>0$ then a country starting below its steady-state relative output would fall increasingly behind over time, with a growth rate that falls increasingly below that of the United States. 
2. Suppose $\beta_{y}=0$. In this case, there is no well-defined steady-state relative output to act as a gravitational force. Instead, a country's growth rate would always equal the steady-stage value:

$$
g_{i}^{*}=g_{1}+\beta_{0}+\beta_{f} F_{i}+\varepsilon_{i}
$$

with no tendency to gravitate towards the frontier rate $g_{1}$. If $g_{i}^{*}<g_{1}$ then the country's relative output would fall continually at the rate $g_{1}-g_{i}^{*}$ with no tendency to stabilize.

Our theory implies that the estimated coefficients $\beta_{y}$ and $\beta_{f}$ in the growth equation (19) should vary across sub-samples grouped according to financial intermediation. Specifically, according to implications 1 and 3, countries where financial intermediation is low enough should have steady-state growth rates different from the frontier rate $g_{1}$, which is only possible in case 2 above where the convergence parameter $\beta_{y}$ equals zero. (In case 1 the growth rate either converges to $g_{1}$ or it does not converge to any limiting value at all.) For such countries implication 3 states that the long-run growth rate should be an increasing function of financial intermediation, which according to (22) implies that the coefficient $\beta_{f}$ should be positive. Thus we should find that among countries with the lowest levels of financial intermediation, $\beta_{y}=0$ and $\beta_{f}>0$.

Likewise the theory implies that countries where financial intermediation is high enough should have growth rates that converge to the frontier rate $g_{1}$, which is only possible if the convergence parameter $\beta_{y}$ is negative. For such countries implication 2 above states that steady-state relative output should be independent of the level of financial intermediation, which according to equation (21) can only happen if the coefficient $\beta_{f}$ equals zero. Thus we should find that among countries with the highest levels of financial intermediation, $\beta_{y}<0$ and $\beta_{f}=0$.

More generally the theory suggests that the higher the average level of financial intermediation in a group of countries the more negative the estimated $\beta_{y}$ should be and the less positive the estimated $\beta_{f}$ should be.

Table 1 below shows the results of estimating the equation using OLS with two groups - - the top and bottom halves with respect to the average level of private credit. ${ }^{21}$ Within the bottom half the convergence parameter $\beta_{y}$ is not significantly different from zero, and the coefficient $\beta_{f}$ of private credit is significantly positive, whereas within the top half the convergence parameter is negative with a high t-statistic and the coefficient of private credit is substantially lower than within the bottom half.

\section{TABLE 1 HERE}

Table 2 shows the results of estimating the same equation using three groups - - the top, middle and bottom thirds with respect to private credit. Again the convergence parameter $\beta_{y}$ decreases and the coefficient $\beta_{f}$ of private credit decreases as we move up the groups. In the top third the convergence parameter is significantly negative and the coefficient of private credit is not significantly different from zero. In the bottom third the convergence

\footnotetext{
${ }^{21}$ The dependent variable in the regressions reported in our empirical results is $g_{i}$ whereas the LHS of (19) and (23) below is $g_{i}-g_{1}$. This discrepancy clearly affects nothing but the constant terms whose values we are not concerned with.
} 
parameter is not significantly different from zero and the coefficient $\beta_{f}$ of private credit is significantly positive. ${ }^{22}$

TABLE 2 HERE

The split-sample regressions thus bear out all of the predictions that we derived from implications $1 \sim 3$ of the theory. ${ }^{23}$

\subsection{Interaction analysis}

As an alternative to these split-sample regressions, which quickly run into serious smallsample problems as we divide the sample into more and more groups, we perform most of our tests using the following interaction analysis. Consider the growth regression: ${ }^{24}$

$$
g_{i}-g_{1}=\beta_{0}+\beta_{f} F_{i}+\beta_{y} \cdot\left(y_{i}-y_{1}\right)+\beta_{f y} \cdot F_{i} \cdot\left(y_{i}-y_{1}\right)+\beta_{x} X_{i}+\varepsilon_{i}
$$

in which the symbols have the same meaning as before and $X_{i}$ is a set of other regressors. This is a standard growth regression except that this time we have included not only the U.S. variables $g_{1}$ and $y_{1}$ but also the interaction variable $F_{i} \cdot\left(y_{i}-y_{1}\right)$.

As before, this regression can be expressed as a difference equation in a country's relative output $\widehat{y}_{i}$. Under the assumption that $\beta_{y}+\beta_{f y} F_{i} \neq 0$ we can write $(23)$ as:

$$
\Delta y_{i}(t)=\lambda_{i} \cdot\left(\widehat{y}_{i}(t)-\widehat{y}_{i}^{*}\right)
$$

with the initial condition:

$$
\widehat{y}_{i}(0)=y_{i}-y_{1}
$$

where this time the steady state relative output $\widehat{y}_{i}^{*}$ is:

$$
\widehat{y}_{i}^{*}=-\frac{\beta_{0}+\beta_{f} F_{i}+\beta_{x} X_{i}+\varepsilon_{i}}{\beta_{y}+\beta_{f y} F_{i}}
$$

and now each country has its own parameter:

$$
\lambda_{i}=(0.35) \cdot\left(\beta_{y}+\beta_{f y} F_{i}\right)
$$

that varies according to its level of financial intermediation.

\footnotetext{
${ }^{22}$ Rioja and Valev (2003) estimated a similar split sample regression using the same data, and came to apparently conflicting results. They split the sample according to per-capita GDP and found that the coefficient of private credit was significantly greater for the top two thirds than the bottom third. The conflict with our results seems to arise mainly from the fact that instead of estimating three separate regressions Rioja and Valev estimated a common regression with slope dummies only on private credit. If we do the same we find the middle third has the largest coefficient of private credit. However, our theory implies that there should be different coefficients for all regressors, not just for private credit, and this implication is borne out by the results of Tables 1 and 2 .

${ }^{23}$ We obtained similar results when instead of using initial relative output we used the productivity gaps described in section 4.3.3 below.

${ }^{24}$ See Appendix C, where we show that equation (23) can be regarded as an approximation to a smooth extension of our theoretical model.
} 
According to (23) a country will converge to the frontier growth rate only if its convergence parameter:

$$
\beta_{y}+\beta_{f y} F_{i}
$$

is negative. Thus the likelihood of convergence will increase with financial development (implication 1 above) if and only if:

$$
\beta_{f y}<0 .
$$

Since this implication constitutes the central proposition of our theoretical model, our main objective in estimating (23) will be to see whether or not the estimated interaction coefficient is indeed significantly negative.

It follows from (25) above that the effect of financial development on steady-state relative output is:

$$
\frac{\partial \widehat{y}_{i}^{*}}{\partial F}=\frac{\beta_{f}+\beta_{f y} \widehat{y}_{i}^{*}}{-\left(\beta_{y}+\beta_{f y} F_{i}\right)} .
$$

Assume that all countries lag the United States in steady state: $\widehat{y}_{i}^{*} \leq 0$. Then according to (23), financial development will have a positive overall effect on the steady-state per-capita GDP of every country that converges only if (27) holds and also the direct effect $\beta_{f}$ of financial development is non-negative. For only then will the numerator of (28) be nonnegative for all converging countries. (The denominator is positive for all such countries.) Moreover, the overall effect of financial development on steady-state relative output will vanish for at least one country (the leader) only if the direct effect is equal to zero:

$$
\beta_{f}=0 .
$$

Our main concern in the paper is that $\beta_{f y}<0$, which is what implication 1 , the effect of finance on convergence, rests on. If we were to find in addition that $\beta_{f}=0$ this would add empirical support to the particular mechanism analyzed in the previous sections, by corroborating implication 2. If we were to find that $\beta_{f}>0$ this would imply that the overall effect (28) of financial development on the level of GDP never vanishes, even for the leader, whereas if we were to find $\beta_{f}<0$ this would imply that the overall effect (28) becomes negative for countries close to the leader. Only when $\beta_{f}=0$ is the overall effect (28) non-negative for all converging countries and zero for some, in accordance with with implication $2 .{ }^{25}$

\subsubsection{Main regression results}

The financial intermediation variable $F$ in equation (23) may be endogenous because of feedback from growth to finance, or because of the common effects of omitted variables on both growth and finance. Moreover, if we maintain the exogeneity of initial relative output then endogeneity of $F$ is likely to entail the endogeneity of the interaction variable $F \cdot\left(y-y_{1}\right)$. To deal with this problem we estimated $(23)$ using instrumental variables, ${ }^{26}$

\footnotetext{
${ }^{25}$ Note that equation (23) does not yield a determinate long-run growth rate for countries that fail to converge, so it is silent on implication 3 above.

${ }^{26}$ We also performed all of the regressions below using the GMM estimator that Davidson and MacKinnon (1993, p.599) call H2SLS, implemented in Stata by the ivgmm0 routine, which allows for heteroskedasticity
} 
instrumenting for $F$ and $F \cdot\left(y-y_{1}\right)$ using legal origins $(L)$ and legal origins interacted with initial relative output $\left(L \cdot\left(y-y_{1}\right)\right)$.

Legal origins is a set of three zero-one variables, used first in the economics literature by La Porta et al. $(1997,1998)$ and further extended to all 71 countries by Levine, Loayza and Beck (2000), indicating whether the country's legal system is based on French, English or German traditions (the omitted case is Scandinavian). La Porta et al. make the case that the main effect of $L$ is on the rights of investors and creditors. Thus Levine, Loayza and Beck argue that $L$ constitutes a valid set of instruments for financial intermediation in a growth regression, because it is clearly exogenous and its main effects on growth should work through financial development. The same argument suggests that the main effect of $L$ should work through an effect much like that of the variable $c$ in our theory representing the cost of defrauding creditors.

We also used the interacted variables $L \cdot\left(y-y_{1}\right)$ as instruments so as to model the interaction term $F \cdot\left(y-y_{1}\right)$. Under the maintained hypothesis that $y-y_{1}$ is exogenous, the validity of $L$ as instruments implies the validity of $L \cdot\left(y-y_{1}\right)$. Table 3 below shows that these instruments account for a significant amount of variation in $F$ and $F \cdot\left(y-y_{1}\right)$. When initial relative output is omitted from the first-stage regression the adjusted $R^{2}$ is 0.56 in the first-stage regression for $F$ and 0.40 in the regression for $F \cdot\left(y-y_{1}\right)$. When initial relative output is included as a regressor the individual coefficients on the external instruments loose significance but together they remain highly significant, as indicated by the F-tests of the hypothesis that all excluded instruments have zero coefficients in the two first-stage regressions.

\section{TABLE 3 HERE}

The results of Table 3 suggest that German legal origins provide the strongest protection of creditor rights and French the weakest, at least for countries close enough to the frontier that the interaction terms $L \cdot\left(y-y_{1}\right)$ are all negligible. For such a country column 1 of Table 3 indicates that having German legal origins instead of Scandinavian raises private credit by 53 percentage points, whereas having French legal origins instead of Scandinavian reduces private credit by 6 percentage points. Column 2 indicates that, again for countries close enough to the frontier, having German legal origins instead of Scandinavian raises private credit by 16 percentage points while having French legal origins rather that Scandinavian reduces private credit by 43 percentage points. In both cases the estimates imply that having German rather than French legal origins raises private credit by 59 percentage points for countries very close to the frontier. As the t-statistics reported in Table 1 make clear the prediction that private credit will be higher under the German system than any other can be made with a high degree of confidence, while the prediction that it will be lower under the French system cannot. ${ }^{27}$

of an unknown kind. The results were not materially different from those generated by the IV estimator, which is equivalent to GMM under the assumption of homoskedasticity, except for some differences noted in footnote 33 below.

${ }^{27}$ These results accord partly with the findings by La Porta et al. (1997). In their Table 2, they use an index from 1 to 4 to measure the degree of creditor protection in different countries. They find an average of 
Table 3 also confirms that private credit will be largest under German legal origins for almost all countries, even those very far from the frontier. Thus the estimates in column 1 make private credit largest under the German system as long as initial relative output lies in the interval from -2.523 to zero, an interval that includes all but 8 of the 71 countries. Below that interval they make private credit largest under the Scandinavian system. The estimates in column 2 make private credit largest under the German system for all countries within the observed range of initial relative outputs. The results do not however uniformly predict that private credit will be lowest under the French system for countries far from the frontier. For while the estimates of column 1 make that prediction for all countries within the observed range of initial relative outputs, the estimates of column 2 predict that private credit will be lowest under Scandinavian rather than French legal origins once initial relative output has fallen below 0.392, which includes all but 7 countries.

The results of the IV estimation are presented in the first column of Table 4 below. They show that financial intermediation interacted with initial relative output has a significantly negative effect $\left(\beta_{f y}=-0.06<0\right)$, bearing out the main implication of the theory to the effect that convergence depends positively on financial development. They also show that the direct effect of financial intermediation is approximately zero, thus bearing out implication 2 above. According to these results the direct effect $\beta_{y}$ of initial relative output on subsequent growth is positive, which introduces a possible element of non-convergence for some countries. Recall however that the overall convergence parameter is $\beta_{y}+\beta_{f y} F$, which must be negative for a country to converge. Thus a country can converge as long as its level of private credit exceeds the critical value:

$$
F^{c}=-\frac{\beta_{y}}{\beta_{f y}}
$$

which according to these estimates equals 25 percent. As we explain in more detail in section 4.3 .2 below, half the countries in our sample have private credit above this critical value.

\section{TABLE 4 HERE}

The next three columns of Table 4 show what happens when three alternative measures of financial intermediation are used. The first is liquid liabilities, which is currency plus demand and interest-bearing liabilities of banks and non-bank financial intermediaries, divided by GDP. This is a commonly used measure of financial intermediation, although it includes liabilities backed by credits to the public sector and may involve double counting. The second alternative measure is bank assets, the value of all credits by banks (but not other financial intermediaries). The third is commercial-central bank, the ratio of commercial bank assets to the sum of commercial plus central bank assets, which has been used

3.11 in English Origin countries, 1.58 in French Origin countries, 2.33 in German Origin countries and 2.00 in Scandinavian Origin countries. But this does not control for GDP per capita. In the following Table 3, they find however that the relationship between creditor rights and indebtedness is more tenuous than that between investor protection and equity financing. 
by others although it is not so much a measure of financial depth as a measure of what fraction of credit is issued by private intermediaries. Our main results $\left(\beta_{f y}<0\right.$ and $\left.\beta_{f}=0\right)$ are robust to all three alternative measures, although in the case of commercial-central bank (our least preferred measure ex ante) the coefficient estimates all lose their statistical significance.

The instruments $L$ and $L \cdot\left(y-y_{1}\right)$ are good predictors of the endogenous variables $F$ and $F \cdot\left(y-y_{1}\right)$ in all cases except where $F$ is defined by commercial-central bank, as indicated by the p-values of the F-test from the first-stage regressions. To be valid instruments $L$ and $L \cdot\left(y-y_{1}\right)$ must also be unaffected by feedback from the growth process, and they must not have a significant effect on growth working through some other variable that has been excluded from the second-stage regression. Since legal origins were determined long before the 1960-95 period over which we are measuring growth we do not have to worry about feedback from the growth process. Also, as indicated above there are strong a priori reasons for believing that their main effects on growth work through financial development. Thus we have good reason for thinking that our instruments are not only strong but valid.

We subjected this a priori reasoning to a standard statistical test. Formally, a set of instruments is valid it they are all uncorrelated with the disturbance term in the growth regression. This is the null hypothesis of the Sargan test, whose p-value is reported in Table $4 .{ }^{28}$ If the instruments are valid this statistic has a $\chi^{2}$ distribution with 4 degrees of freedom, since there are 6 excluded instruments $\left(L\right.$ and $\left.L \cdot\left(y-y_{1}\right)\right)$ but only 2 endogenous variables $\left(F\right.$ and $\left.F \cdot\left(y-y_{1}\right)\right)$. In no case does the test reject the validity of the instruments at conventional significance levels.

As a further check we also redid the estimation using as instruments the initial (1960) value $F_{0}$ of financial intermediation and $F_{0} \cdot\left(y-y_{1}\right)$, instead of $L$ and $L \cdot\left(y-y_{1}\right)$. The results are presented in the next four columns of Table 4 . The coefficients remained close to zero on financial intermediation and significantly negative on the interaction variable $F \cdot\left(y-y_{1}\right)$, except again when financial intermediation was measured by commercial-central bank, in which case all coefficients became insignificantly different from zero.

As expected, $F_{0}$ and $F_{0} \cdot\left(y-y_{1}\right)$ are good predictors of $F$ and $F \cdot\left(y-y_{1}\right)$; this is indicated by the low p-values of the first-stage F-tests. There is also little reason for believing that the main effects of these instruments on growth work through channels other than financial development. However, they may be affected by feedback from the growth process, in the sense that countries in which growth has been strong in the sample period may also have had strong growth at the beginning of the period, so that they are likely to have high values of $F_{0}$ for the same reason that they are likely to have high values of $F$. Because of this, and also because we cannot apply the Sargan test for the validity of these instruments, ${ }^{29}$ we choose to work from here on with our legal origins instruments.

On the other hand, a Wu-Hausman test of the exogeneity of $F$ and $F \cdot\left(y-y_{1}\right)$ in the growth equation was inconclusive, with a p-value of 0.18 , suggesting that perhaps we could have used OLS consistently. The last four columns of Table 4 show that similar results follow using OLS on all four measures of financial intermediation, adding further corroboration to

\footnotetext{
${ }^{28}$ The Sargan test statistic is the uncentered $R^{2}$ from regressing the IV residuals on the excluded instruments.

${ }^{29}$ The Sargan test is not applicable in these regressions because there are only as many excluded instruments (2) as endogenous variables, and hence the IV residuals are identically orthogonal to the instruments.
} 
implications 1 and 2 of our theoretical model.

We checked the robustness of our results by reestimating our basic equation (23), with $F$ defined as private credit and without any $X$ variables, omitting all countries with a residual more than 3 times the standard error of the equation in the original IV estimation (just one country), then omitting all with a residual more than 2 times (4 countries) and then all with a residual more than 1 time (17 countries). The crucial coefficient $\beta_{f y}$ did not change sign and its statistical significance increased at each step, while $\beta_{f}$ remained not significantly different from zero.

We also checked for robustness against other regressors by reestimating the equation using the same alternative conditioning sets $X$ as used by Levine, Loayza and Beck (2000). The basic conditioning set includes just average years of schooling in 1960. The policy conditioning set includes the basic conditioning set plus measures of government size, inflation, the black market exchange-rate premium and openness to trade. The full conditioning set includes the policy conditioning set plus measures of political stability and ethnic diversity. The results of this robustness check are presented in Table 5 below.

\section{TABLE 5 HERE}

As this table indicates, the sign, size and significance of the crucial coefficients $\beta_{f}$ and $\beta_{f y}$ remain virtually unchanged across alternative conditioning sets, in the case of all 3 definitions of financial intermediation. (We have dropped commercial-central bank partly because of our a priori doubts about its suitability and also because we already know from Table 4 above that it does not behave as predicted by the theory.) Moreover, as indicated by the Sargan test results, the instruments $L$ and $L \cdot\left(y-y_{1}\right)$ continue always to pass the standard test of being uncorrelated with the residuals of the growth equation.

\subsubsection{Which countries converge?}

The fact that the estimated direct effect $\beta_{y}$ of initial relative output $\left(y-y_{1}\right)$ is positive implies that according to these results countries with extremely low financial intermediation will fail to join the convergence club, since the overall effect of $y-y_{1}$ on growth (the "convergence parameter") equals $\beta_{y}+\beta_{f y} F$, which is positive when $F$ is close enough to zero. Figure 6 below shows our estimates (from the first column of Table 4) of this convergence parameter as a function of private credit, over the observed range of $F$, with 2-standard deviation bands. According to these estimates 36 of the 71 countries have a negative convergence parameter and 35 have a positive one. In this sense, the estimated value of the

crucial interaction parameter $\beta_{f y}$ is not only statistically significant but also quantitatively large enough to account for different convergence experiences across countries in the sample. 


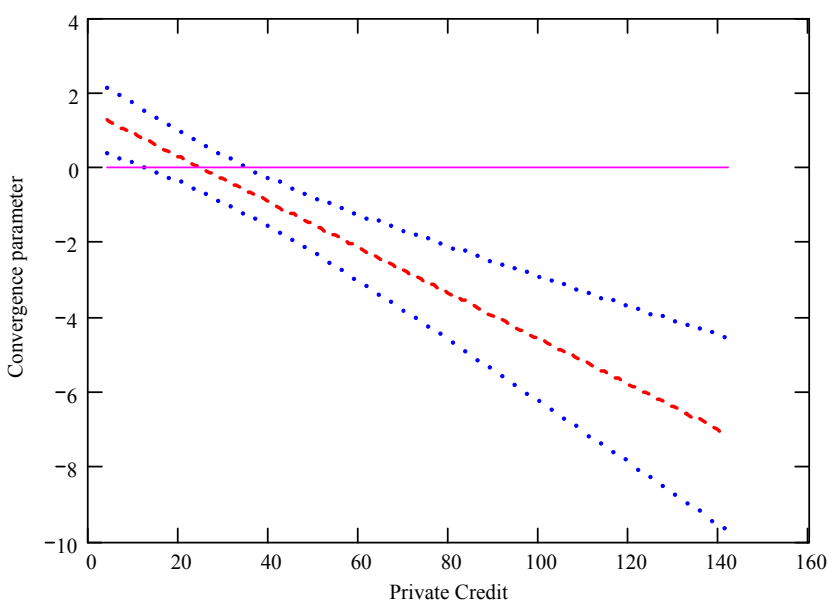

Figure 6: Estimated convergence parameter over the observed rate of private credit. Positive values imply nonconvergence.

Table 6 classifies countries into three convergence groups, according to whether their convergence parameter is at least 2 standard deviations above or below zero. There are 30 countries in the group most likely to converge, including all the OECD countries except Belgium, whose estimated parameter was the smallest of all the positive ones. There are 7 countries in the group most likely to diverge, all them extremely poor, leaving 34 countries in the middle with a convergence parameter within 2 standard deviations of zero. The estimated value of this convergence parameter for a country with $F$ equal to the average value of private credit across all countries is -0.82 , which by the usual calculation implies a convergence rate of almost $5 \%$ per year.

TABLE 6 HERE

\subsubsection{Productivity}

As a further test of our theory we examined whether the effects of $F$ and $F \cdot\left(y-y_{1}\right)$ on percapita GDP growth were working through productivity growth, as implied by the theory, instead of working just through capital accumulation. So we re-estimated the basic growth equation (23) using productivity growth as the dependent variable instead of growth in per-capita GDP, and interpreting $y$ as the log of aggregate productivity in 1960 instead of the log of per-capita GDP. The results are presented in Table 7 below for the case where financial intermediation is measured by our preferred variable, private credit. ${ }^{30}$

\section{TABLE 7 HERE}

\footnotetext{
${ }^{30}$ Estimates using liquid liabilities and bank assets yield the same conclusions.
} 
In the first four rows our productivity measure is multi-factor productivity, taken from Benhabib and Spiegel (2002), which covers almost all the same countries for the same 19601995 period. This measure does not consider schooling as an input. As constructed by Benhabib and Spiegel it equals GDP per person, divided by capital per person to the power $1 / 3$. This would be a measure of Hicks-neutral productivity if the aggregate production function were Cobb-Douglas with a capital coefficient of $1 / 3$ and per-capita labor input were constant. In order to make our results comparable to those using per-capita GDP we multiplied the $\log$ of this original productivity measure by 1.5 to make it a measure of Harrod-neutral (labor-augmenting) productivity, whose steady-state growth rate should equal the steady-state growth rate of per-capita GDP.

According to Table 7 the crucial coefficient $\beta_{f a}$ of $F \cdot\left(\ln a-\ln a_{1}\right)$ is between 85 and 95 percent of the analogous estimates of the interaction coefficient reported in the previous Table 5, and it remains statistically significant. Also the coefficient $\beta_{f}$ of $F$ remains not significantly different from zero. As before, the results are stable across conditioning sets and the legal origins instruments $L$ and $L \cdot\left(\ln a-\ln a_{1}\right)$ pass the Sargan test at conventional significance levels.

The next four rows of Table 7 repeat the same exercise using a measure of total factor productivity that takes education into account, under the assumption of a constant $7 \%$ rate of return to a year of schooling, using a macro-Mincer approach. The coefficients are almost the same size and have almost the same statistical significance as before, although the Sargan test for the validity of our legal-origins instruments is now inconclusive.

The similarity of these results to those using per-capita GDP are what we would expect from the theory developed above. The fact that the coefficients are somewhat smaller than when per-capita GDP is used may simply reflect the fact that productivity is not as well measured as GDP in cross country data, because of large measurement errors in investment data (Pritchett, 2000) underlying the regressors $\ln a-\ln a_{1}$ and $F \cdot\left(\ln a-\ln a_{1}\right)$ in the productivity-growth equation. The possibility of such measurement errors is the main reason we prefer to use per-capita GDP rather than productivity in our main empirical work, another reason being that we can work with a larger sample (71 countries rather than 65 or 66$)$.

\subsubsection{Alternative explanations of divergence}

Perhaps what prevents poor countries from converging in growth rate is not lack of financial development but lack of education, as implied by Howitt and Mayer-Foulkes (2002) or Benhabib and Spiegel (2002), or perhaps financial development matters for growth only because it facilitates investment in schooling, as in Galor and Zeira (1993). Or maybe divergence is explained by some other variable that is associated with a low initial level of income. ${ }^{31}$ Table 8 begins to address these questions by checking whether the effect of finance on convergence is robust to including a possible effect of schooling or of initial relative output on convergence.

\footnotetext{
${ }^{31}$ Another interpretation of our finding of a negative interaction coefficient $\beta_{f y}$ is that entrepreneurs in poor countries have relatively few alternatives to borrowing from financial intermediaries because of weak or non-existent equity and bond markets. To the extent that weak equity and bond markets are a by-product of weak investor protection, the same factor that our theory is focusing on, this alternative interpretation is complementary with ours.
} 
First we included as an additional regressor the square of initial relative output, $\left(y-y_{1}\right)^{2}$. If this term were to have a significant negative coefficient $\beta_{y y}$ it might indicate that what keeps poor countries from joining the convergence club is just being poor to start with, or something other than finance that is correlated with being poor to start with. For in that case the overall effect of initial relative output on growth would be $\beta_{y}+\beta_{f y} F+2 \beta_{y y} \cdot\left(y-y_{1}\right)$, which would be positive when both $F$ and $y$ are small enough. As shown in the second column of Table 8, this effect was not significantly different from zero. Comparison with the first column shows that the inclusion of the quadratic term also did not materially affect the estimated values or significance levels of the crucial parameters $\beta_{f}$ and $\beta_{f y}$. Nor did it affect the validity of the instruments $L$ and $L \cdot\left(y-y_{1}\right)$ according to the p-value of the Sargan test.

\section{TABLE 8 HERE}

Next we included as additional regressors not $\left(y-y_{1}\right)^{2}$ but the Schooling variable School60 - average years of schooling in 1960 - and also the interaction term School60 . $\left(y-y_{1}\right)$. If this interaction term were to have a significant negative coefficient $\beta_{\text {sy }}$ it might indicate that lack of education is what keeps poor countries from joining the convergence club, since the overall effect of initial relative output on growth would be $\beta_{y}+\beta_{f y} F+\beta_{s y}$. School60, which would be positive when both $F$ and School60 are small enough. As shown in the third column, the estimated $\beta_{s y}$ is not significantly different from zero, and the estimated values and significance levels of the crucial parameters $\beta_{f}$ and $\beta_{f y}$ were not materially affected by the inclusion of this additional interaction term. The next column shows that the same results hold when we use as our education variable average years of secondary schooling instead of School60. Again the direct and interaction terms are insignificant and the crucial parameters $\beta_{f}$ and $\beta_{f y}$ retained their sign and significance. The next column of Table 8 show that the same is true when we use as our schooling variable $h y$, the ratio of human capital to GDP in 1985, as measured by Klenow and Rodríguez-Clare (1997). The final two columns show that the same is true when we use the growth in average years of schooling from 1960 to 1995 and the growth in the Klenow/Rodríguez-Clare human-capital ratio from 1960 to 1985 .

The results of Table 8 show once more the robustness of financial intermediation as a source of (non)convergence and provide further support for our theoretical model. They also provide further evidence of the validity of our legal origins instruments $L$ and $L \cdot\left(y-y_{1}\right)$, in two different ways. First, as shown by the reported p-values, the instruments continue to pass the Sargan test even in the presence of these alternative regressors. Second and more fundamentally, the results address the main question that might be raised concerning the instruments, namely whether their effects on growth might be working through some channel other than finance, despite our a priori reasons for thinking otherwise and despite the results of the Sargan test, which might not be powerful against plausible alternatives. For example, Acemoglu (2003) has argued that the main effects of legal origins is to foster institutions that promote growth by protecting citizens from the power of the state. Perhaps it is the correlation between our instruments $L$ and $L \cdot\left(y-y_{1}\right)$ on the one hand and these alternative channels of influence on the other that is producing our estimated effects of $F$ 
and $F \cdot\left(y-y_{1}\right)$. The results of Table 8 show that if this is true then that other channel is not likely to be schooling or human capital, for if it was then the direct inclusion of these variables in the growth regression should soak up the explanatory power of the fitted values of $F$ and $F \cdot\left(y-y_{1}\right)$, which clearly they do not.

It should be mentioned however that the results of Table 8 do not imply, even if taken at face value, that schooling is unimportant in the growth process. Instead they imply that if schooling matters then it does so in a way that works through financial development. For example, a better educated population may lower the costs of innovation, ${ }^{32}$ thus making the credit constraint less binding. Additionally a better educated population with higher incomes would supply more loanable funds, provide more creditworthy borrowers and thus encourage investments in financial intermediation that also generate growth. Indeed this is suggested by the first-stage regressions of the IV estimations underlying Table 8, in which schooling is often a significant determinant of financial development.

Table 9 below shows the results of performing the same exercise using a large number of alternative variables along with their interaction with initial relative output. The first group of variables consists of geographic measures - - an African dummy, distance to the equator, the fraction of population within 100 miles of an ocean-navigable waterway, and the fraction of population in the tropics - - which according to one school of thought should have significant long-term effect on growth and/or the level of per-capita GDP. The next group consists of various measures of public health - - average mortality rate, average life expectancy and the Malaria Ecology variable constructed by Kiszewski et al. (2003) and used by Sachs (2003). Next we included a variety of policy variables that have been suggested in the literature as possible sources of non-convergence - - openness to international trade, an index of business regulations, the size of the government sector, the black market premium and the average inflation rate. Next there is a set of variables reflecting political and social stability - - ethnic fractionalization, revolutions and coups, and political assassination. Finally there is a long list of institutional variables that might possibly be channels through which legal origins affect growth - - an index of state-owned enterprises, bureaucratic efficiency, corruption, the rule of law, property rights, the risk of expropriation, civil liberties, the average of Kaufmann, Kraay and Zoido-Lobaton's (1999) 6 measures of governance, Hall and Jones's (1999) index of social infrastructure, Bockstette, Chanda and Putterman's (2002) measure of length of experience with statehood, Adelman and Morris's index of social capability as extended by Temple and Johnson (1998) and Acemoglu, Johnson and Robinson's (2001) settler-mortality variable.

\section{TABLE 9 HERE}

If our results were fragile, or if our legal instruments were working on growth and convergence primarily through some channel other than financial development then the addition of at least some of these variables and their interaction with initial relative output should destroy the explanatory power of $F \cdot\left(y-y_{1}\right)$ in our growth regression, or make the coefficient $\beta_{f}$ on $F$ significantly different from zero. But the results of Table 9 show otherwise.

\footnotetext{
${ }^{32}$ This is what happens when human capital passes a threshold value in the model of Howitt and MayerFoulkes (2002).
} 
The estimated sign of the coefficient $\beta_{f y}$ on $F \cdot\left(y-y_{1}\right)$ remains negative in all cases. It is also statistically significant in all cases except when the alternative variable is settler mortality, a case in which the number of observations is quite small and multicollinearity of the instruments makes the parameter estimates unreliable.

We explored this single exception further by pooling the 38 ex-colonial countries for which we have data on settler mortality with the other 33 countries (non-ex-colonies) in our dataset, so as to raise the sample size to 71 . We set settler mortality equal to zero for the non-ex-colonies and included in the regression a dummy for non-ex-colony and an interaction between this dummy and initial relative output. This formulation assumes that being an ex-colony has an effect on growth and convergence but not on the growth effects of having more financial intermediation. The results are displayed in the last column of table 9 . They confirm implication 1, to the effect that the direct coefficient of private credit should be zero, and suggests that the only exception in Table 9 to the finding of a significantly negative value of the interaction coefficient $\beta_{f y}$ may be attributable to a small sample bias, which the analysis of this paragraph has sought to correct.

Also, according to Table 9 in all cases the coefficient $\beta_{f}$ of $F$ remains not significantly different from zero when these alternative variables are included in the regression. Moreover, the only case in which the interaction between an alternative variable and initial relative output was statistically significant was that of bureaucratic efficiency, which came in with the wrong sign, indicating that convergence is less likely with a more efficient bureaucracy.

We interpret these results as a further indication that lack of financial development accounts for the failure of some countries to converge to the growth rate of the global technology frontier, a further corroboration of our theory, and a further indication of the validity of our legal origins instruments. If some factor other than financial development is primarily responsible for determining a country's convergence status then that other factor must not be one that is represented by any of the commonly cited explanatory variables included in Tables 8 and $9 .{ }^{33}$

\section{Conclusion}

The paper has developed and tested a Schumpeterian model of cross country convergence with financial constraints. The model is consistent with the broad facts of convergence and divergence since the 19th Century. It implies that all countries above some critical level of financial development should converge in growth rates, and that in such countries financial development has a positive but eventually vanishing effect on steady-state GDP. These implications were tested by estimating a cross-country growth regression with an interaction term between financial intermediation and the country's initial relative output. As predicted, the coefficient of this term is negative and highly significant, and the direct effect of financial intermediation is not significantly different from zero.

\footnotetext{
${ }^{33}$ When we re-estimated the coefficients in Tables 8 and 9 using the GMM procedure indicated in footnote 26 above the direct effect of finance became statistically significant in 5 of the regressions with institutional variables, and the interaction terms with three alternative institutional variables became statistically significant at the 10 percent level, but never at the 1 percent level. However, the main implication of the theory continued to be supported by the results: specifically, the crucial interaction coefficient $\beta_{f y}$ remained negative at the 1 percent significance level in all cases except again that of settler mortality.
} 
Why some countries fail to converge in growth rates despite the possibility of technology transfer has been a puzzle. In combination with the theoretical results of Howitt (2000), Acemoglu, Aghion and Zilibotti (2002) and Howitt and Mayer-Foulkes (2002) our theoretical results show that Schumpeterian growth theory provides a framework for analyzing a variety of forces that contribute to nonconvergence. Our empirical results suggest that financial development is among the most powerful of these forces, especially considering that educational attainment, initial relative output and a large number of other candidate variables do not have an analogous effect when included in the same regression with financial intermediation. ${ }^{34}$

A further test of the theory would be to examine the sectoral composition of innovation across countries with different levels of financial development. Financial development should be especially favorable to innovation in R\&D-intensive sectors, where technology transfer requires much external finance. In future work we plan to test for industry-specific effects of financial development much the same way that Rajan and Zingales (1998) did, except using $R \& D$ intensity rather than their more general measure of dependency on external finance.

\footnotetext{
${ }^{34}$ Our results suggest that a country might escape divergence by using FDI as a substitute for lending to local entrepreneurs. However, the results of Alfaro et al. (2003) suggest that FDI and local finance are complements. Specifically, they find that FDI has a significant effect on growth only when interacted with finance. This is consistent with the view that FDI results in technology transfer only when complemented by the local entrepreneurial investments at the heart of our theory, which investments are impeded by lack of financial development.
} 


\section{TABLE 1 : Split-Sample Regressions ( Two-way )}

$\begin{array}{llll} & \text { Constant } & F & y-y_{1} \\ \text { Top half } & -0.020 & 0.020^{*} & -1.615^{\star * *} \\ & (-0.02) & (1.98) & (-4.33) \\ \text { Bottom half } & 0.579 & 0.095^{\star * *} & 0.619 \\ & (0.50) & (2.73) & (1.67)\end{array}$

Dependent variable is average growth rate of per-capita GDP 1960-1995. Estimation by OLS.

$F$ is average private credit 1960-1995, $y-y_{1}$ is log per-capita GDP 1960 relative to the United States.

Sample size is 71 countries. Sample split according to values of $F$. (t-statistics in parentheses)

*** significant at $1 \%$ level

** significant at $5 \%$ level

* significant at $10 \%$ level

\section{TABLE 2 : Split-Sample Regressions ( Three-way )}

$\begin{array}{lcll} & \text { Constant } & F & y-y_{1} \\ \text { Top third } & 1.208 & 0.004 & -1.759^{* * *} \\ & (1.31) & (0.37) & (-5.16) \\ \text { Middle third } & -2.274 & 0.119^{* *} & -0.285 \\ & (-1.29) & (2.66) & (-0.67) \\ \text { Bottom third } & -0.685 & 0.154^{* *} & 0.347 \\ & (-0.39) & (2.78) & (0.61)\end{array}$

Dependent variable is average growth rate of per-capita GDP 1960-1995. Estimation by OLS.

$F$ is average private credit 1960-1995, $y-y_{1}$ is log per-capita GDP 1960 relative to the United States.

Sample size is 71 countries. Sample split according to values of $F$. (t-statistics in parentheses)

\footnotetext{
*** significant at $1 \%$ level

** significant at $5 \%$ level

* significant at $10 \%$ level
} 


\section{Table 3 : First-Stage Regressions using Legal Origins as Instruments}

\begin{tabular}{|c|c|c|c|c|}
\hline Dependent variable & $F$ & $F$ & $F\left(y-y_{1}\right)$ & $F\left(y-y_{1}\right)$ \\
\hline Const & $\begin{array}{l}59.95^{\star * *} \\
(7.07)\end{array}$ & $\begin{array}{l}96.63^{* * *} \\
(3.43)\end{array}$ & $\begin{array}{c}-28.50^{* *} \\
(-2.53)\end{array}$ & $\begin{array}{l}-14.59 \\
(-0.39)\end{array}$ \\
\hline Eng & $\begin{array}{c}6.40 \\
(0.55)\end{array}$ & $\begin{array}{l}-30.28 \\
(-1.04)\end{array}$ & $\begin{array}{c}5.33 \\
(0.55)\end{array}$ & $\begin{array}{c}-8.59 \\
(-0.22)\end{array}$ \\
\hline Fre & $\begin{array}{c}-6.06 \\
(-0.51)\end{array}$ & $\begin{array}{l}-42.74 \\
(-1.46)\end{array}$ & $\begin{array}{c}-0.38 \\
(-0.02)\end{array}$ & $\begin{array}{l}-14.30 \\
(-0.36)\end{array}$ \\
\hline Ger & $\begin{array}{l}52.85^{\star \star *} \\
(3.44)\end{array}$ & $\begin{array}{l}16.17 \\
(0.52)\end{array}$ & $\begin{array}{l}12.96 \\
(0.63)\end{array}$ & $\begin{array}{c}-0.96 \\
(-0.02)\end{array}$ \\
\hline Eng $\left(y-y_{1}\right)$ & $\begin{array}{l}18.90^{* * *} \\
(4.53)\end{array}$ & $\begin{array}{l}-53.60 \\
(-1.01)\end{array}$ & $\begin{array}{l}12.59^{* *} \\
(2.27)\end{array}$ & $\begin{array}{l}-14.92 \\
(-0.21)\end{array}$ \\
\hline Fre $\left(y-y_{1}\right)$ & $\begin{array}{l}15.44^{* * *} \\
(3.32)\end{array}$ & $\begin{array}{l}-57.06 \\
(-1.07)\end{array}$ & $\begin{array}{c}6.01 \\
(0.97)\end{array}$ & $\begin{array}{l}-21.50 \\
(-0.30)\end{array}$ \\
\hline $\operatorname{Ger}\left(y-y_{1}\right)$ & $\begin{array}{l}20.95^{\star *} \\
(2.31)\end{array}$ & $\begin{array}{l}-51.56 \\
(-0.96)\end{array}$ & $\begin{array}{l}61.83^{\star * *} \\
(5.14)\end{array}$ & $\begin{array}{l}34.32 \\
(0.47)\end{array}$ \\
\hline$y-y_{1}$ & & $\begin{array}{l}72.50 \\
(1.37)\end{array}$ & & $\begin{array}{l}27.51 \\
(0.39)\end{array}$ \\
\hline adjusted $R^{2}$ & 0.56 & 0.57 & 0.40 & 0.39 \\
\hline$p$-value of $F$ test & 0.00 & 0.00 & 0.00 & 0.00 \\
\hline
\end{tabular}

Notes: Estimation by OLS. Sample size is 71 countries. (t-statistics in parentheses)

$F$ is average private credit 1960-95.

$y-y_{1}$ is the log of per-capita GDP in 1960 relative to the United States.

Eng, Fre, Ger are respectively indicators of English, French and German legal origins.

The null hypothesis of the $\mathrm{F}$ test is that the coefficients of all regressors other than $y-y_{1}$ are zero.

*** significant at $1 \%$ level

${ }^{* *}$ significant at $5 \%$ level

* significant at $10 \%$ level 
Table 4: Growth, Financial Intermediation, and Initial GDP Gap

\begin{tabular}{|c|c|c|c|c|c|c|c|c|c|c|c|c|}
\hline & \multicolumn{4}{|c|}{ IV using Legal Origins } & \multicolumn{4}{|c|}{ IV using Initial Values } & \multicolumn{4}{|c|}{ OLS } \\
\hline & $\begin{array}{c}\text { Private } \\
\text { Credit }\end{array}$ & $\begin{array}{c}\text { Liquid } \\
\text { Liabilities }\end{array}$ & $\begin{array}{c}\text { Bank } \\
\text { Assets }\end{array}$ & $\begin{array}{c}\text { Commer - } \\
\text { Central } \\
\end{array}$ & $\begin{array}{c}\text { Private } \\
\text { Credit } \\
\end{array}$ & $\begin{array}{c}\text { Liquid } \\
\text { Liabilities } \\
\end{array}$ & $\begin{array}{c}\text { Bank } \\
\text { Assets } \\
\end{array}$ & $\begin{array}{c}\text { Commer - } \\
\text { Central } \\
\end{array}$ & $\begin{array}{c}\text { Private } \\
\text { Credit }\end{array}$ & $\begin{array}{c}\text { Liquid } \\
\text { Liabilities } \\
\end{array}$ & $\begin{array}{c}\text { Bank } \\
\text { Assets }\end{array}$ & $\begin{array}{c}\text { Commer - } \\
\text { Central } \\
\end{array}$ \\
\hline Constant & $\begin{array}{l}2.07^{* *} \\
(2.06)\end{array}$ & $\begin{array}{c}2.85^{\star} \\
(1.84)\end{array}$ & $\begin{array}{r}1.85^{*} \\
(1.79)\end{array}$ & $\begin{array}{c}0.60 \\
(0.04)\end{array}$ & $\begin{array}{l}1.69^{* *} \\
(2.36)\end{array}$ & $\begin{array}{l}1.97^{* *} \\
(2.16)\end{array}$ & $\begin{array}{l}1.74^{* *} \\
(2.29)\end{array}$ & $\begin{array}{c}3.75 \\
(0.71)\end{array}$ & $\begin{array}{l}2.20^{* * *} \\
(3.43)\end{array}$ & $\begin{array}{l}2.71^{* * *} \\
(3.26)\end{array}$ & $\begin{array}{l}2.07^{* * *} \\
(2.89)\end{array}$ & $\begin{array}{c}3.06 \\
(0.94)\end{array}$ \\
\hline$F$ & $\begin{array}{c}-0.01 \\
(-0.93)\end{array}$ & $\begin{array}{l}-0.03 \\
(-1.04)\end{array}$ & $\begin{array}{c}-0.02 \\
(-1.07)\end{array}$ & $\begin{array}{c}0.00 \\
(0.00)\end{array}$ & $\begin{array}{l}-0.00 \\
(-0.23)\end{array}$ & $\begin{array}{c}0.01 \\
(0.11)\end{array}$ & $\begin{array}{c}-0.02 \\
(-0.11)\end{array}$ & $\begin{array}{l}-0.01 \\
(-0.22)\end{array}$ & $\begin{array}{c}-0.01 \\
(-1.29)\end{array}$ & $\begin{array}{l}-0.02 \\
(-1.07)\end{array}$ & $\begin{array}{l}-0.11 \\
(-0.96)\end{array}$ & $\begin{array}{c}-0.01 \\
(-0.29)\end{array}$ \\
\hline$y-y_{1}$ & $\begin{array}{l}1.51^{* * *} \\
(3.14)\end{array}$ & $\begin{array}{l}2.65^{\star * *} \\
(3.12)\end{array}$ & $\begin{array}{l}1.89^{* * *} \\
(3.57)\end{array}$ & $\begin{array}{c}7.17 \\
(1.04)\end{array}$ & $\begin{array}{c}0.79^{* *} \\
(2.29)\end{array}$ & $\begin{array}{l}0.97^{* *} \\
(2.02)\end{array}$ & $\begin{array}{c}0.81^{* *} \\
(2.11)\end{array}$ & $\begin{array}{c}0.57 \\
(0.25)\end{array}$ & $\begin{array}{l}1.30^{* * *} \\
(4.05)\end{array}$ & $\begin{array}{l}1.62^{* * *} \\
(3.81)\end{array}$ & $\begin{array}{l}1.35^{\star * *} \\
(3.74)\end{array}$ & $\begin{array}{c}2.42^{*} \\
(1.68)\end{array}$ \\
\hline$F\left(y-y_{1}\right)$ & $\begin{array}{l}-0.06^{\star * *} \\
(-5.35)\end{array}$ & $\begin{array}{l}-0.08^{* * *} \\
(-3.68)\end{array}$ & $\begin{array}{l}-0.08^{* * *} \\
(-5.07)\end{array}$ & $\begin{array}{c}-0.11 \\
(-1.29)\end{array}$ & $\begin{array}{l}-0.04^{* * *} \\
(-3.71)\end{array}$ & $\begin{array}{l}-0.02^{* *} \\
(-2.48)\end{array}$ & $\begin{array}{l}-0.03^{* * *} \\
(-3.14)\end{array}$ & $\begin{array}{l}-0.00 \\
(-0.01)\end{array}$ & $\begin{array}{l}-0.05^{\star * *} \\
(-7.02)\end{array}$ & $\begin{array}{l}-0.04^{* * *} \\
(-4.74)\end{array}$ & $\begin{array}{l}-0.05^{\star \star *} \\
(-5.94)\end{array}$ & $\begin{array}{l}-0.03^{*} \\
(-1.81)\end{array}$ \\
\hline $1^{\text {st }}$-stage $\mathrm{p}: F$ & 0.00 & 0.01 & 0.00 & 0.27 & 0.00 & 0.00 & 0.00 & 0.00 & & & & \\
\hline $1^{\text {st }}$-stage p: $F\left(y-y^{1}\right)$ & 0.00 & 0.07 & 0.00 & 0.51 & 0.00 & 0.00 & 0.00 & 0.00 & & & & \\
\hline$p$ of Sargan test & 0.57 & 0.25 & 0.86 & 0.97 & & & & & & & & \\
\hline $\mathrm{R}^{2}$ & & & & & & & & & 0.54 & 0.48 & 0.49 & 0.23 \\
\hline \# obs & 71 & 71 & 71 & 71 & 60 & 58 & 60 & 65 & 71 & 71 & 71 & 71 \\
\hline \multicolumn{13}{|c|}{$\begin{array}{l}\text { Notes: Dependent variable: average growth rate of per-capita real GDP, } 1960-1995 . \\
F \text { is average Financial Intermediation } 1960-95, y-y_{1} \text { is the log of per-capita GDP in } 1960 \text { relative to the United States. } \\
\text { (t-statistics in parentheses) }\end{array}$} \\
\hline $\begin{array}{l}{ }^{* * *} \text { significant at } 1 \% \text { le } \\
{ }^{* *} \text { significant at } 5 \% \text { le } \\
{ }^{*} \text { significant at } 10 \%\end{array}$ & & & & & & & & & & & & \\
\hline
\end{tabular}




\section{Table 5: Robustness to Alternative Conditioning Sets}

\begin{tabular}{|c|c|c|c|c|c|}
\hline $\begin{array}{l}\text { Measure of financial } \\
\text { internediation }\end{array}$ & $\begin{array}{c}\text { Conditioning } \\
\text { set }\end{array}$ & $F$ & $F\left(y-y_{1}\right)$ & $\begin{array}{c}\text { Sargan test } \\
\text { p-value }\end{array}$ & $\begin{array}{c}\text { \# of } \\
\text { observations }\end{array}$ \\
\hline \multirow[t]{4}{*}{ Private credit } & Empty $^{a}$ & $\begin{array}{l}-0.015 \\
(-0.93)\end{array}$ & $\begin{array}{l}-0.061^{* * *} \\
(-5.35)\end{array}$ & 0.57 & 71 \\
\hline & Basic $^{b}$ & $\begin{array}{l}-0.018 \\
(-1.12)\end{array}$ & $\begin{array}{l}-0.062^{* * *} \\
(-5.49)\end{array}$ & 0.49 & 71 \\
\hline & Policy ${ }^{c}$ & $\begin{array}{l}-0.013 \\
(-0.68)\end{array}$ & $\begin{array}{l}-0.063^{* * *} \\
(-5.10)\end{array}$ & 0.78 & 63 \\
\hline & Full $^{d}$ & $\begin{array}{l}-0.016 \\
(-0.78)\end{array}$ & $\begin{array}{l}-0.063^{* * *} \\
(-4.62)\end{array}$ & 0.66 & 63 \\
\hline \multirow[t]{4}{*}{ Liquid Liabilities } & Empty & $\begin{array}{l}-0.030 \\
(-1.04)\end{array}$ & $\begin{array}{l}-0.076^{\star * *} \\
(-3.68)\end{array}$ & 0.25 & 71 \\
\hline & Basic & $\begin{array}{l}-0.030 \\
(-1.04)\end{array}$ & $\begin{array}{l}-0.074^{* * *} \\
(-3.64)\end{array}$ & 0.24 & 71 \\
\hline & Policy & $\begin{array}{l}-0.030 \\
(-0.99)\end{array}$ & $\begin{array}{l}-0.073^{* * *} \\
(-3.55)\end{array}$ & 0.48 & 63 \\
\hline & Full & $\begin{array}{l}-0.030 \\
(-0.90)\end{array}$ & $\begin{array}{l}-0.073^{* * *} \\
(-3.55)\end{array}$ & 0.48 & 63 \\
\hline \multirow[t]{4}{*}{ Bank Assets } & Empty & $\begin{array}{l}-0.020 \\
(-1.07)\end{array}$ & $\begin{array}{l}-0.081^{* * *} \\
(-5.07)\end{array}$ & 0.86 & 71 \\
\hline & Basic & $\begin{array}{l}-0.018 \\
(-1.04)\end{array}$ & $\begin{array}{l}-0.080^{* * *} \\
(-5.01)\end{array}$ & 0.84 & 71 \\
\hline & Policy & $\begin{array}{l}-0.020 \\
(-1.03)\end{array}$ & $\begin{array}{l}-0.081^{* * *} \\
(-4.85)\end{array}$ & 0.91 & 63 \\
\hline & Full & $\begin{array}{l}-0.020 \\
(-1.12)\end{array}$ & $\begin{array}{l}-0.081^{* * *} \\
(-4.46)\end{array}$ & 0.88 & 63 \\
\hline
\end{tabular}

Notes: Dependent variable: average growth rate of per-capita GDP 1960-1995. ( t-statistics in parentheses) $y-y_{1}$ is the log of per-capita GDP in 1960 relative to the United States.

$F$ is average financial intermediation 1960-1995.

Estimation by IV using legal origins and legal origins interacted with $y-y_{1}$ as instruments for $F$ and $F\left(y-y_{1}\right)$

a $y-y_{1}$

b empty set plus schooling 1960.

${ }^{c}$ basic set plus government size, inflation, black market premium and openness to trade.

${ }^{d}$ policy set plus indicators of revolutions and coups, political assassinations and ethnic diversity.

*** significant at $1 \%$ level 
Table 6: Convergence Club Membership

\begin{tabular}{|c|c|c|}
\hline 1 Probably converges & $2 \underline{\text { Uncertain convergence }}$ & 3 Probably diverges \\
\hline Switzerland & Iceland & Liberia \\
\hline Japan & Venezuela & Syrian Arab Republic \\
\hline United States & Trinidad \& Tobago & Nepal \\
\hline Sweden & Chile & Haiti \\
\hline Netherlands & Senegal & Ghana \\
\hline Norway & Philippines* & Sierra Leone \\
\hline Germany & Belgium & Zaire \\
\hline France & Jamaica & \\
\hline South Africa & Mauritius & \\
\hline Korea & Honduras & \\
\hline Austria & $\mathrm{Fiji}$ & \\
\hline Spain & Zimbabwe & \\
\hline Cyprus & Mexico & \\
\hline Canada & El Salvador & \\
\hline Italy & Kenya & \\
\hline Taiwan & Colombia & \\
\hline Portugal & Togo & \\
\hline Australia & Costa Rica & \\
\hline Finland & Brazil & \\
\hline Ireland & Uruguay & \\
\hline Thailand & Papua New Guinea & \\
\hline Malaysia & Pakistan & \\
\hline UK & Guyana & \\
\hline Malta & India & \\
\hline Denmark & Dominican Republic & \\
\hline Barbados & Ecuador & \\
\hline Panama & Sri Lanka & \\
\hline New Zealand & Argentina & \\
\hline Israel & Paraguay & \\
\hline Greece & Bangladesh & \\
\hline & Peru & \\
\hline & Guatemala & \\
\hline & Bolivia & \\
\hline & Niger & \\
\hline
\end{tabular}

Notes: Financial development decreases, and hence the estimated convergence parameter increases, as you move down each list and then to the right.

*The estimated convergence parameter is negative (indicating convergence) in countries above (and including) the Philippines and positive (indicating divergence) in countries below the Philippines. 


\section{Table 7: Productivity and Alternative Conditioning Sets}

\begin{tabular}{|c|c|c|c|c|c|}
\hline Dependent variable & $\begin{array}{c}\text { Conditioning } \\
\text { set }\end{array}$ & $F$ & $F\left(\operatorname{Ina}-\ln a_{1}\right)$ & $\begin{array}{l}\text { Sargan test } p \text { - } \\
\text { value }\end{array}$ & $\begin{array}{c}\text { \# of } \\
\text { observations }\end{array}$ \\
\hline \multirow[t]{4}{*}{$\begin{array}{l}\text { Multi-factor productivity } \\
\text { growth }\end{array}$} & Empty $^{a}$ & $\begin{array}{l}-0.004 \\
(-0.43)\end{array}$ & $\begin{array}{l}-0.051^{* * *} \\
(-4.19)\end{array}$ & 0.31 & 65 \\
\hline & Basic $^{b}$ & $\begin{array}{l}-0.007 \\
(-0.77)\end{array}$ & $\begin{array}{l}-0.050^{* * *} \\
(-4.28)\end{array}$ & 0.57 & 65 \\
\hline & Policy $^{c}$ & $\begin{array}{l}-0.008 \\
(-0.75)\end{array}$ & $\begin{array}{l}-0.057^{* * *} \\
(-4.15)\end{array}$ & 0.45 & 59 \\
\hline & Full $^{d}$ & $\begin{array}{l}-0.009 \\
(-0.78)\end{array}$ & $\begin{array}{l}-0.057^{* * *} \\
(-3.46)\end{array}$ & 0.57 & 59 \\
\hline \multirow[t]{4}{*}{$\begin{array}{l}\text { Total-factor productivity } \\
\text { growth }\end{array}$} & Empty & $\begin{array}{l}-0.002 \\
(-0.19)\end{array}$ & $\begin{array}{l}-0.052 * * * \\
(-3.59)\end{array}$ & 0.14 & 66 \\
\hline & Basic & $\begin{array}{l}-0.000 \\
(-0.01)\end{array}$ & $\begin{array}{l}-0.053^{* * *} \\
(-3.64)\end{array}$ & 0.12 & 66 \\
\hline & Policy & $\begin{array}{l}-0.004 \\
(-0.30)\end{array}$ & $\begin{array}{l}-0.0511^{* * *} \\
(-3.53)\end{array}$ & 0.25 & 63 \\
\hline & Full & $\begin{array}{l}-0.002 \\
(-0.13)\end{array}$ & $\begin{array}{l}-0.052 * * * \\
(-3.22)\end{array}$ & 0.21 & 63 \\
\hline
\end{tabular}

Notes: Dependent variable: productivity growth rate 1960-95.

$F$ is average private credit 1960-1995.

Ina - Ina ${ }_{1}$ is the log of productivity in 1960 relative to the United States.

Estimation by IV using legal origins and legal origins interacted with Ina - Ina ${ }_{1}$ as instruments for $F$ and $F$ (Ina - Ina 1 ). (t-statistics in parentheses)

a Ina - Ina 1

${ }^{\mathrm{b}}$ empty set plus schooling 1960.

${ }^{\mathrm{c}}$ basic set plus government size, inflation, black market premium and openness to trade.

d policy set plus indicators of revolutions and coups, political assassinations and ethnic diversity.

*** significant at $1 \%$ level 
Table 8: Test for Other Interactions (Part 1)

\begin{tabular}{|c|c|c|c|c|c|c|c|}
\hline$x=$ & Empty & $y-y_{1}$ & School 60 & $\mathrm{Sec}$ & hy & gschool & ghy \\
\hline$F$ & $\begin{array}{l}-0.015 \\
(-0.93)\end{array}$ & $\begin{array}{l}-0.015 \\
(-0.71)\end{array}$ & $\begin{array}{l}-0.017 \\
(-0.86)\end{array}$ & $\begin{array}{l}-0.019 \\
(-1.01)\end{array}$ & $\begin{array}{l}-0.001 \\
(-0.07)\end{array}$ & $\begin{array}{l}-0.015 \\
(-0.88)\end{array}$ & $\begin{array}{l}-0.005 \\
(-0.40)\end{array}$ \\
\hline$F\left(y-y_{1}\right)$ & $\begin{array}{l}-0.061^{* * *} \\
(-5.35)\end{array}$ & $\begin{array}{l}-0.061^{* * *} \\
(-4.05)\end{array}$ & $\begin{array}{l}-0.061^{* * *} \\
(-3.70)\end{array}$ & $\begin{array}{l}-0.057^{* * *} \\
(-3.71)\end{array}$ & $\begin{array}{l}-0.041^{* * *} \\
(-3.36)\end{array}$ & $\begin{array}{l}-0.061^{* * *} \\
(-4.90)\end{array}$ & $\begin{array}{l}-0.043^{* * *} \\
(-3.65)\end{array}$ \\
\hline$x$ & & $\begin{array}{l}1.711 \\
(0.97)\end{array}$ & $\begin{array}{l}0.158 \\
(0.96)\end{array}$ & $\begin{array}{l}0.442 \\
(0.96)\end{array}$ & $\begin{array}{l}0.910 \\
(0.44)\end{array}$ & $\begin{array}{l}0.229 \\
(0.55)\end{array}$ & $\begin{array}{l}0.328 \\
(0.46)\end{array}$ \\
\hline$x\left(y-y_{1}\right)$ & & $\begin{array}{l}0.063 \\
(0.15)\end{array}$ & $\begin{array}{l}0.027 \\
(0.19)\end{array}$ & $\begin{array}{l}0.211 \\
(0.61)\end{array}$ & $\begin{array}{l}-1.836 \\
(-1.30)\end{array}$ & $\begin{array}{l}0.036 \\
(0.22)\end{array}$ & $\begin{array}{l}-0.464 \\
(-1.18)\end{array}$ \\
\hline $\begin{array}{l}\text { Sargan } \\
\text { test } p- \\
\text { value }\end{array}$ & 0.57 & 0.57 & 0.45 & 0.59 & 0.15 & 0.61 & 0.88 \\
\hline \# obs & 71 & 71 & 71 & 69 & 70 & 71 & 70 \\
\hline \multicolumn{8}{|c|}{$\begin{array}{l}\text { Notes: Dependent variable: average growth rate of per-capita GDP } 1960-1995 . \\
F \text { is average private credit } 1960-1995 .\end{array}$} \\
\hline \multicolumn{8}{|c|}{$y-y_{1}$ is the log of per-capita GDP in 1960 relative to the United States. } \\
\hline \multicolumn{8}{|c|}{$\begin{array}{l}\text { Estimation by IV using legal origins and legal origins interacted with } y-y_{1} \\
\text { as instruments for } F \text { and } F\left(y-y_{1}\right) \text {. (t-statistics in parentheses) }\end{array}$} \\
\hline $\begin{array}{r}\text { *** } \text { significa } \\
\text { ** significa } \\
\text { * significa }\end{array}$ & $\begin{array}{l}\text { at } 1 \% \text { level } \\
\text { at } 5 \% \text { level } \\
\text { at } 10 \% \text { leve }\end{array}$ & & & & & & \\
\hline
\end{tabular}




\section{Table 9: Test for Other Interactions (Part 2)}

\begin{tabular}{|c|c|c|c|c|c|c|c|c|c|c|c|c|c|c|c|}
\hline & \multicolumn{4}{|c|}{ Geography } & \multicolumn{3}{|c|}{ Health } & \multicolumn{5}{|c|}{ Policy variables } & \multicolumn{3}{|c|}{ Political-social stability } \\
\hline$x=$ & Africa & Eq. Dist. & pop100cr & tropop & avgmort & avgexpect & me & trade & Bus. reg. & gov & bmp & pi & avelf & revc & assass \\
\hline$F$ & $\begin{array}{l}-0.008 \\
(-0.48)\end{array}$ & $\begin{array}{l}-0.120 \\
(-0.70)\end{array}$ & $\begin{array}{l}-0.015 \\
(-0.89)\end{array}$ & $\begin{array}{l}-0.012 \\
(-0.70)\end{array}$ & $\begin{array}{l}-0.011 \\
(-0.61)\end{array}$ & $\begin{array}{l}-0.010 \\
(-0.51)\end{array}$ & $\begin{array}{l}-0.006 \\
(-0.38)\end{array}$ & $\begin{array}{l}-0.013 \\
(-0.83)\end{array}$ & $\begin{array}{l}-0.010 \\
(-0.64)\end{array}$ & $\begin{array}{l}-0.020 \\
(-1.19)\end{array}$ & $\begin{array}{l}-0.018 \\
(-0.94)\end{array}$ & $\begin{array}{l}-0.016 \\
(-0.83)\end{array}$ & $\begin{array}{l}-0.011 \\
(-0.63)\end{array}$ & $\begin{array}{l}-0.020 \\
(-1.15)\end{array}$ & $\begin{array}{l}-0.019 \\
(-1.21)\end{array}$ \\
\hline$F\left(y-y_{1}\right)$ & $\begin{array}{l}-0.053^{\star \star \star} \\
(-4.34)\end{array}$ & $\begin{array}{c}-0.046^{* * *} \\
(-2.98)\end{array}$ & $\begin{array}{l}-0.063^{\star \star \star} \\
(-4.62)\end{array}$ & $\begin{array}{c}-0.053^{* * *} \\
(-4.05)\end{array}$ & $\begin{array}{c}-0.046^{\star \star *} \\
(-3.09)\end{array}$ & $\begin{array}{l}-0.047^{* * *} \\
(-3.10)\end{array}$ & $\begin{array}{c}-0.046^{\star * *} \\
(-3.83)\end{array}$ & $\begin{array}{c}-0.062^{* * *} \\
(-5.27)\end{array}$ & $\begin{array}{c}-0.052^{* * *} \\
(-3.71)\end{array}$ & $\begin{array}{c}-0.067^{* * *} \\
(-5.34)\end{array}$ & $\begin{array}{l}-0.065^{\star * *} \\
(-4.97)\end{array}$ & $\begin{array}{c}-0.060^{* * *} \\
(-4.68)\end{array}$ & $\begin{array}{c}-0.056^{\star * *} \\
(-4.21)\end{array}$ & $\begin{array}{c}-0.063^{* * *} \\
(-5.22)\end{array}$ & $\begin{array}{c}-0.062^{* * *} \\
(-5.47)\end{array}$ \\
\hline$x$ & $\begin{array}{l}-0.973 \\
(-0.55)\end{array}$ & $\begin{array}{l}1.270 \\
(0.58)\end{array}$ & $\begin{array}{l}-0.849 \\
(-0.56)\end{array}$ & $\begin{array}{l}-0.470 \\
(-0.40)\end{array}$ & $\begin{array}{l}-0.006 \\
(-1.62)\end{array}$ & $\begin{array}{l}0.090 \\
(1.15)\end{array}$ & $\begin{array}{l}0.048 \\
(0.31)\end{array}$ & $\begin{array}{l}0.007 \\
(0.38)\end{array}$ & $\begin{array}{l}-0.300 \\
(-0.50)\end{array}$ & $\begin{array}{l}0.124 \\
(1.48)\end{array}$ & $\begin{array}{l}-0.017 \\
(-1.00)\end{array}$ & $\begin{array}{l}-0.007 \\
(-0.26)\end{array}$ & $\begin{array}{l}1.013 \\
(0.52)\end{array}$ & $\begin{array}{l}-2.836 \\
(-1.12)\end{array}$ & $\begin{array}{l}-0.700 \\
(-0.73)\end{array}$ \\
\hline$x\left(y-y_{1}\right)$ & $\begin{array}{l}0.229 \\
(0.29)\end{array}$ & $\begin{array}{l}-1.105 \\
(-0.66)\end{array}$ & $\begin{array}{l}-0.265 \\
(-0.38)\end{array}$ & $\begin{array}{l}0.271 \\
(0.43)\end{array}$ & $\begin{array}{l}0.001 \\
(0.26)\end{array}$ & $\begin{array}{l}0.005 \\
(0.13)\end{array}$ & $\begin{array}{l}0.049 \\
(0.83)\end{array}$ & $\begin{array}{l}0.001 \\
(0.09)\end{array}$ & $\begin{array}{l}-0.247 \\
(-0.68)\end{array}$ & $\begin{array}{l}0.067 \\
(1.27)\end{array}$ & $\begin{array}{l}-0.008 \\
(-1.00)\end{array}$ & $\begin{array}{l}-0.003 \\
(-0.17)\end{array}$ & $\begin{array}{l}0.952 \\
(0.97)\end{array}$ & $\begin{array}{l}-1.539 \\
(-1.13)\end{array}$ & $\begin{array}{l}-0.169 \\
(-0.28)\end{array}$ \\
\hline $\begin{array}{l}\text { Sargan p- } \\
\text { value } \\
\text { \# obs }\end{array}$ & $\begin{array}{c}0.39 \\
71\end{array}$ & $\begin{array}{c}0.59 \\
70\end{array}$ & $\begin{array}{c}0.66 \\
67\end{array}$ & $\begin{array}{c}0.78 \\
67\end{array}$ & $\begin{array}{c}0.41 \\
64\end{array}$ & $\begin{array}{c}0.40 \\
64\end{array}$ & $\begin{array}{c}0.57 \\
67\end{array}$ & $\begin{array}{c}0.73 \\
66\end{array}$ & $\begin{array}{c}0.38 \\
66\end{array}$ & $\begin{array}{c}0.58 \\
64\end{array}$ & $\begin{array}{c}0.77 \\
67\end{array}$ & $\begin{array}{c}0.55 \\
71\end{array}$ & $\begin{array}{c}0.33 \\
71\end{array}$ & $\begin{array}{c}0.58 \\
71\end{array}$ & $\begin{array}{c}0.68 \\
71\end{array}$ \\
\hline
\end{tabular}

\begin{tabular}{|c|c|c|c|c|c|c|c|c|c|c|c|c|c|}
\hline \\
\hline$x=$ & soe & bureau & corrupt & rulelaw & pr.rights & exprisk & civil lib. & $k k z$ & infra & statehist & socap & setmortal & setmortal $^{\mathrm{a}}$ \\
\hline$F$ & $\begin{array}{l}-0.014 \\
(-0.76)\end{array}$ & $\begin{array}{l}-0.018 \\
(-0.76)\end{array}$ & $\begin{array}{l}-0.023 \\
(-1.08)\end{array}$ & $\begin{array}{l}-0.019 \\
(-0.91)\end{array}$ & $\begin{array}{l}-0.016 \\
(-0.77)\end{array}$ & $\begin{array}{l}-0.022 \\
(-0.95)\end{array}$ & $\begin{array}{l}-0.014 \\
(-0.69)\end{array}$ & $\begin{array}{l}-0.024 \\
(-1.02)\end{array}$ & $\begin{array}{l}-0.028 \\
(-1.08)\end{array}$ & $\begin{array}{l}-0.015 \\
(-0.82)\end{array}$ & $\begin{array}{l}-0.066 \\
(-1.50)\end{array}$ & $\begin{array}{l}-0.011 \\
(-0.11)\end{array}$ & $\begin{array}{l}-0.021 \\
(-1.03)\end{array}$ \\
\hline$F\left(y-y_{1}\right)$ & $\begin{array}{c}-0.056^{\star * *} \\
(-4.05)\end{array}$ & $\begin{array}{c}-0.060^{* * *} \\
(-3.59)\end{array}$ & $\begin{array}{c}-0.058^{\star * *} \\
(-3.54)\end{array}$ & $\begin{array}{c}-0.054^{* * *} \\
(-3.03)\end{array}$ & $\begin{array}{c}-0.055^{\star \star *} \\
(-2.68)\end{array}$ & $\begin{array}{l}-0.053^{\star *} \\
(-2.19)\end{array}$ & $\begin{array}{c}-0.057^{* * *} \\
(-3.58)\end{array}$ & $\begin{array}{c}-0.061^{* \star *} \\
(-2.91)\end{array}$ & $\begin{array}{c}-0.062^{\star * *} \\
(-2.85)\end{array}$ & $\begin{array}{c}-0.055^{\star \star *} \\
(-4.51)\end{array}$ & $\begin{array}{c}-0.079^{* * *} \\
(-2.53)\end{array}$ & $\begin{array}{l}-0.110 \\
(-1.22)\end{array}$ & $\begin{array}{l}-0.060^{* * *} \\
(-4.24)\end{array}$ \\
\hline$x$ & $\begin{array}{l}0.080 \\
(0.32)\end{array}$ & $\begin{array}{l}0.571^{*} \\
(1.69)\end{array}$ & $\begin{array}{l}0.231 \\
(0.99)\end{array}$ & $\begin{array}{l}0.533^{*} \\
(1.98)\end{array}$ & $\begin{array}{l}0.452 \\
(0.68)\end{array}$ & $\begin{array}{l}0.900^{*} \\
(1.98)\end{array}$ & $\begin{array}{l}-0.212 \\
(-0.63)\end{array}$ & $\begin{array}{l}1.012 \\
(1.30)\end{array}$ & $\begin{array}{c}3.88 \\
(1.33)\end{array}$ & $\begin{array}{l}0.058 \\
(0.04)\end{array}$ & $\begin{array}{l}0.695 \\
(0.53)\end{array}$ & $\begin{array}{l}0.012 \\
(0.61)\end{array}$ & $\begin{array}{l}0.001 \\
(0.11)\end{array}$ \\
\hline$x\left(y-y_{1}\right)$ & $\begin{array}{l}0.068 \\
(0.47)\end{array}$ & $\begin{array}{l}0.401^{*} \\
(2.00)\end{array}$ & $\begin{array}{l}0.103 \\
(0.73)\end{array}$ & $\begin{array}{l}0.237 \\
(1.29)\end{array}$ & $\begin{array}{l}0.230 \\
(0.50)\end{array}$ & $\begin{array}{l}0.345 \\
(0.95)\end{array}$ & $\begin{array}{l}0.043 \\
(0.25)\end{array}$ & $\begin{array}{l}0.321 \\
(0.60)\end{array}$ & $\begin{array}{l}0.895 \\
(0.46)\end{array}$ & $\begin{array}{l}-0.812 \\
(-1.05)\end{array}$ & $\begin{array}{l}-0.095 \\
(-0.19)\end{array}$ & $\begin{array}{l}0.004 \\
(0.67)\end{array}$ & $\begin{array}{l}0.001 \\
(0.23)\end{array}$ \\
\hline $\begin{array}{l}\text { Sargan } p- \\
\text { value } \\
\# \text { of obs }\end{array}$ & $\begin{array}{c}0.37 \\
66\end{array}$ & $\begin{array}{c}0.95 \\
38\end{array}$ & $\begin{array}{c}0.65 \\
66\end{array}$ & $\begin{array}{c}0.89 \\
42\end{array}$ & $\begin{array}{c}0.36 \\
66\end{array}$ & $\begin{array}{c}0.88 \\
42\end{array}$ & $\begin{array}{c}0.84 \\
70\end{array}$ & $\begin{array}{c}0.71 \\
70\end{array}$ & $\begin{array}{c}0.76 \\
69\end{array}$ & $\begin{array}{c}0.87 \\
67\end{array}$ & $\begin{array}{c}\alpha \\
40\end{array}$ & $\begin{array}{c}\alpha \\
38\end{array}$ & $\begin{array}{c}0.77 \\
71\end{array}$ \\
\hline
\end{tabular}

Notes: Dependent variable: average growth rate of per-capita GDP 1960-1995. ( t-statistics in parentheses) $F$ is average private credit $1960-1995$.

$y-y_{1}$ is the log of per-capita GDP in 1960 relative to the United States. See Appendix D for description of other variables.

$\alpha$ : In these cases multicollinearity forced Stata to drop some of the instruments.

${ }^{a}$ Sample augmented to include non-ex-colonies, as described in the text.

*** significant at $1 \%$ level

** significant at $5 \%$ level

* significant at $10 \%$ level 


\section{Appendix A: Slower convergence}

In this Appendix we indicate how the theoretical analysis would be changed if the innovation technology took the more general form:

$$
A_{t}(i)=\left\{\begin{array}{cc}
b \bar{A}_{t}+(1-b) A_{t-1} & \text { with probability } \mu_{t} \\
A_{t-1}(i) & \text { with probability } 1-\mu_{t}
\end{array}\right\},
$$

where $A_{t}=\int_{0}^{1} A_{t}(i) d i$ is again the average domestic productivity at date $t$ and $b$ is a real number between 0 and 1 . The basic model of the text assumes an extreme special case of (30), namely $b=1$.

As before, the equilibrium innovation probability $\mu_{t}$ will be the same across all intermediate sectors, so we can integrate (30) over all sectors $i$ to produce the following dynamic equation for average productivity:

$$
A_{t}=\mu_{t}\left[b \bar{A}_{t}+(1-b) A_{t-1}\right]+\left(1-\mu_{t}\right) A_{t-1},
$$

or equivalently

$$
A_{t}=\mu_{t} b \bar{A}_{t}+\left(1-\mu_{t} b\right) A_{t-1} .
$$

We shall maintain the assumption that the $\mathrm{R} \& \mathrm{D}$ cost is proportional to the technological target, so that we now have

$$
n_{t-1}=\widetilde{n}\left(\mu_{t}\right)\left[b \bar{A}_{t}+(1-b) A_{t-1}\right]
$$

where as before

$$
\widetilde{n}\left(\mu_{t}\right)=\eta \mu_{t}+\delta \mu_{t}^{2} / 2 .
$$

We first look at the perfect credit market case, and then we turn our attention to the case where firms are credit-constrained.

Perfect credit markets: In this case, the equilibrium innovation rate $\mu_{t}$ will be chosen so as to maximize the expected net payoff:

$$
\beta \mu_{t} \pi\left[b \bar{A}_{t}+(1-b) A_{t-1}\right]-\widetilde{n}\left(\mu_{t}\right)\left[b \bar{A}_{t}+(1-b) A_{t-1}\right] .
$$

We thus get

$$
\mu_{t}=\mu^{*} \equiv \frac{\beta \pi-\eta}{\delta}
$$

as before. Putting this into (31), dividing both sides by $\bar{A}_{t}$ and updating, we see that distance to the frontier now evolves according to:

$$
a_{t+1}=\mu^{*} b+\frac{\left(1-\mu^{*} b\right)}{1+g} a_{t}
$$

which is the same as the evolution equation (8) in the text, except with $\mu^{*} b$ replacing $\mu^{*}$. By the same logic, therefore, $a_{t}$ will converge monotonically to its unique steady-state value:

$$
a^{*}=\frac{(1+g) \mu^{*} b}{g+\mu^{*} b}
$$


which is strictly lower than when $b=1$.

Credit constrained firms: In this case, the equilibrium innovation rate $\mu_{t}$ solves:

$$
\max _{\mu_{t}}\left\{\beta \mu_{t} \pi\left[b \bar{A}_{t}+(1-b) A_{t-1}\right]-\widetilde{n}\left(\mu_{t}\right)\left[b \bar{A}_{t}+(1-b) A_{t-1}\right]\right\}
$$

subject to the credit constraint:

$$
\widetilde{n}\left(\mu_{t}\right)\left[b \bar{A}_{t}+(1-b) A_{t-1}\right] \leq \frac{1+r}{1+r-c} w_{t-1}=\omega(c)(1+g) A_{t-1}
$$

where as before:

$$
\omega(c)=\frac{(1+r)(1-\alpha) \zeta}{(1+r-c)(1+g)} .
$$

When this constraint binds:

$$
\widetilde{n}\left(\mu_{t}\right)=\omega(c) \frac{a_{t-1}}{b+\frac{1-b}{1+g} a_{t-1}}=\omega(c) \xi\left(a_{t-1}\right) .
$$

where:

$$
\xi\left(a_{t-1}\right)=\frac{a_{t-1}}{b+\frac{1-b}{1+g} a_{t-1}}
$$

so that $\mu_{t}=\widetilde{\mu}\left(\omega(c) \xi\left(a_{t-1}\right)\right)$, where as before:

$$
\widetilde{\mu}(n)=\frac{\sqrt{\eta^{2}+2 \delta n}-\eta}{\delta} .
$$

The credit constraint in turn will bind whenever

$$
a_{t-1}<\widetilde{a}(c),
$$

where the critical value $\widetilde{a}(c)$ satisfies:

$$
\mu^{*}=\widetilde{\mu}(\omega(c) \xi(a)) .
$$

In that case from (31) we obtain that $a_{t}$ will be determined over time according to:

$$
a_{t}=\widetilde{\mu}\left(\omega(c) \xi\left(a_{t-1}\right)\right) b+\frac{\left(1-\widetilde{\mu}\left(\omega(c) \xi\left(a_{t-1}\right)\right) b\right)}{1+g} a_{t-1} \equiv \widetilde{F}_{2}\left(a_{t-1}\right) .
$$

From here on, the convergence analysis will remain qualitatively the same as in our basic framework. In particular, using the fact that

$$
\xi(0)=0 ; \xi^{\prime}(0)=\frac{1}{b}
$$

and that

$$
\widetilde{\mu}^{\prime}(0)=\frac{1}{\eta}
$$

we obtain

$$
\widetilde{F}_{2}^{\prime}(0)=\frac{\omega(c)}{\eta}+\frac{1}{1+g}
$$


Divergence will again occur whenever

$$
\widetilde{F}_{2}^{\prime}(0)<1
$$

or equivalently whenever

$$
\omega(c)<\frac{\eta g}{1+g},
$$

in which case the country's asymptotic growth rate will be:

$$
\widehat{G}=(1+g) \widetilde{F}_{2}^{\prime}(0)-1=(1+g) \omega(c) / \eta \in(0,1) .
$$

Comparison with the results at the end of section 3.1 in the text shows that the conditions for membership in group 3 and the asymptotic growth rate within that group are exactly the same as in the case of $b=1$.

\section{Appendix B: Endogenous size of innovations}

Suppose that an innovator at date $t-1$ can target any productivity level $B_{t}(i)=B_{t}$ less than or equal to the frontier technology $\bar{A}_{t}$ at date $t$. In line with our basic model, the $\mathrm{R} \& \mathrm{D}$ cost of achieving $B_{t}$ with probability $\mu_{t}$ is assumed to be equal to $\widetilde{n}\left(\mu_{t}\right) B_{t}$. Now, consider an innovator who is investing a given amount $N_{t-1}$ on innovation. If she targets the productivity level $B_{t}$, her innovation probability $\mu_{t}$ will be:

$$
\mu_{t}=\widetilde{\mu}\left(\frac{N_{t-1}}{B_{t}}\right)
$$

On the other hand the post-innovation profit if productivity level $B_{t}$ is achieved equals:

$$
\tilde{\pi}\left(B_{t}\right)=\pi B_{t}
$$

Thus her expected discounted profit will be:

$$
\Pi\left(B_{t}\right)=\beta \widetilde{\mu}\left(\frac{N_{t-1}}{B_{t}}\right) \pi B_{t}-N_{t-1},
$$

Because the innovation function $\widetilde{\mu}$ has an elasticity less than one, therefore expected discounted profit is strictly increasing in $B_{t}$ :

$$
\Pi^{\prime}\left(B_{t}\right)=\left(\widetilde{\mu}\left(\frac{N_{t-1}}{B_{t}}\right)-\widetilde{\mu}^{\prime}\left(\frac{N_{t-1}}{B_{t}}\right) \frac{N_{t-1}}{B_{t}}\right) \beta \pi>0 .
$$

Therefore whatever amount $N_{t-1}$ is being invested the entrepreneur will choose to target the highest possible technology level: $B_{t}=\bar{A}_{t}$. It follows that targeting $\bar{A}_{t}$ is optimal not only for a credit constrained entrepreneur but also for an entrepreneur with access to unlimited funds at the rate of interest $r$, because in either case if $\left(\widetilde{N}, \widetilde{B}_{t}\right)$ is the optimal choice of $\left(N_{t-1}, B_{t}\right)$ then $\widetilde{B}$ must be the optimal choice of $B_{t}$ given that $N_{t-1}=\widetilde{N}$. 


\section{Appendix C: Approximating the model with the estimated equation}

In this appendix we show how our estimation equation (23) can be derived from a smoothed version of the dynamic equation (16) in our theoretical model. We can first reexpress (16) as:

$$
a_{t+1}=\mu\left(\omega a_{t}\right)+\frac{1-\mu\left(\omega a_{t}\right)}{1+g} a_{t}
$$

where:

$$
\mu\left(\omega a_{t}\right)=\left\{\begin{array}{ll}
\widetilde{\mu}\left(\omega a_{t}\right) & \text { if } \omega a_{t}<n^{*} \\
\mu^{*}=\widetilde{\mu}\left(n^{*}\right) & \text { otherwise }
\end{array}\right\}
$$

$\omega$ is the financial multiplier defined by (14) in the text, and the innovation function $\widetilde{\mu}$, defined by (11) in the text, is increasing and strictly concave.

Now, let us consider the same dynamic equation (32), but where we replace the kinked function $\mu(\omega a)$ by a function $\lambda(\omega a)$ which is very similar but not kinked. To be consistent with implication 2 of section 3.2 above, suppose that $\lambda$ is strictly increasing for all values of $\omega a$ up to $a_{1} \omega_{1}$, where $\omega_{1}$ is the leader's financial multiplier and $a_{1}$ is the leader's initial normalized productivity, but that the effect of financial innovation just vanishes for the leader. That is:

1. $\lambda$ is strictly concave with

$$
\lambda^{\prime \prime}(\omega a) \leq-\epsilon<0
$$

for all $\omega a \leq a_{1} \omega_{1}$

2. $\lambda$ is infinitely differentiable and

3. $\lambda^{\prime}(\omega a)=0$ for $\omega a \geq a_{1} \omega_{1}$.

Thus, let us start from the dynamic equation

$$
a_{t+1}=\lambda\left(\omega a_{t}\right)+\frac{1-\lambda\left(\omega a_{t}\right)}{1+g} a_{t} .
$$

The rate of productivity growth $G_{t}$ between dates $t$ and $t+1$ satisfies:

$$
1+G_{t}=\frac{A_{t+1}}{A_{t}}=\frac{a_{t+1} \bar{A}_{t+1}}{a_{t} \bar{A}_{t}}=\frac{a_{t+1}}{a_{t}}(1+g),
$$

which, using (33), can be rewritten as:

$$
G_{t}=G\left(\omega, a_{t}\right)=\lambda\left(\omega a_{t}\right)\left[\frac{1+g}{a_{t}}-1\right] .
$$

Using a second-order Taylor expansion, we can approximate $G$ in the neighborhood of the frontier point $\left(\omega_{1}, a_{1}\right)$ as:

$$
G(\omega, a) \cong\left\{\begin{array}{l}
G\left(\omega_{1}, a_{1}\right)+G_{\omega}\left(\omega_{1}, a_{1}\right)\left(\omega-\omega_{1}\right)+G_{a}\left(\omega_{1}, a_{1}\right)\left(a-a_{1}\right) \\
+\frac{1}{2} G_{\omega \omega}\left(\omega_{1}, a_{1}\right)\left(\omega-\omega_{1}\right)^{2} \\
+\frac{1}{2} G_{a a}\left(\omega_{1}, a_{1}\right)\left(a-a_{1}\right)^{2} \\
+G_{\omega a}\left(\omega_{1}, a_{1}\right)\left(\omega-\omega_{1}\right)\left(a-a_{1}\right)
\end{array}\right\}
$$


where the subscripts on $G$ denote partial derivatives. This in turn can be reexpressed as a quadratic polynomial in the percentage technology gap:

$$
\Delta=\frac{a-a_{1}}{a_{1}} \cong \ln a-\ln a_{1} .
$$

We thus obtain the convergence equation:

$$
G(\omega, a) \cong\left\{\begin{array}{c}
G\left(\omega_{1}, a_{1}\right)+G_{\omega}\left(\omega_{1}, a_{1}\right)\left(\omega-\omega_{1}\right)+a_{1} G_{a}\left(\omega_{1}, a_{1}\right) \Delta \\
+\frac{1}{2} G_{\omega \omega}\left(\omega_{1}, a_{1}\right)\left(\omega-\omega_{1}\right)^{2} \\
+\frac{1}{2}\left(a_{1}\right)^{2} G_{a a}\left(\omega_{1}, a_{1}\right) \Delta^{2} \\
+a_{1} G_{\omega a}\left(\omega_{1}, a_{1}\right)\left(\omega-\omega_{1}\right) \Delta
\end{array}\right\} .
$$

After substituting for $G$ and its partial derivatives at $(\omega, a)=\left(\omega_{1}, a_{1}\right)$, using the fact that

$$
\lambda^{\prime}\left(\omega_{1} a_{1}\right)=0 \text { and } \lambda\left(\omega_{1} a_{1}\right)=\mu^{*}
$$

and assuming that the leader starts in steady state, with $G\left(\omega_{1}, a_{1}\right)=g$, we end up with the convergence equation:

$$
G(\omega, a) \cong\left\{\begin{array}{l}
g-\frac{\mu^{*}(1+g)}{a_{1}} \Delta \\
+\frac{1}{2}\left(a_{1}\right)^{2} \lambda^{\prime \prime}\left(\omega_{1} a_{1}\right)\left(\frac{1+g}{a_{1}}-1\right)\left(\omega-\omega_{1}\right)^{2} \\
+\frac{1}{2}\left[2 \mu^{*}\left(\frac{1+g}{a_{1}}\right)+\left(\omega_{1} a_{1}\right)^{2} \lambda^{\prime \prime}\left(\omega_{1} a_{1}\right)\left(\frac{1+g}{a_{1}}-1\right)\right] \Delta^{2} \\
+\left(a_{1}\right)^{2} \omega_{1} \lambda^{\prime \prime}\left(\omega_{1} a_{1}\right)\left(\frac{1+g}{a_{1}}-1\right)\left(\omega-\omega_{1}\right) \Delta .
\end{array}\right\} .
$$

In particular: (i) the direct coefficient of $\left(\omega-\omega_{1}\right)$ is equal to zero because it is proportional to $\lambda^{\prime}\left(\omega_{1} a_{1}\right)$; and (ii) the interaction coefficient of $\left(\omega-\omega_{1}\right) \Delta$, namely

$$
\left(a_{1}\right)^{2} \omega_{1} \lambda^{\prime \prime}\left(\omega_{1} a_{1}\right)\left(\frac{1+g}{a_{1}}-1\right)
$$

is strictly negative because

$$
\lambda^{\prime \prime}\left(\omega_{1} a_{1}\right) \leq-\epsilon<0
$$

The equation (23) that we have estimated differs from (34) in three respects. First it uses the financial intermediation variable $F$ instead of $\omega$. Since $F$ is a linear transformation of $\omega^{35}$ this does not alter the form of the equation. Second, it uses the log of per-capita GDP $(y)$ instead of the log of productivity $(\ln a)$. Third it omits the pure quadratic terms, in $\Delta^{2}$

\footnotetext{
${ }^{35}$ From our discussion in Section 3.3, we know that the ratio $F$ of intermediary lending to GDP, which is our empirical measure of financial development, satisfies:$$
F / 0.7+1=\frac{1+r}{1+r-c}
$$

so that

$$
\omega=\frac{(1-\alpha) \zeta}{1+g}(F / 0.7+1) .
$$
}


and $\left(\omega-\omega_{1}\right)^{2}$. The sign restrictions (i) and (ii) derived above are precisely the restrictions (27) and (29) that we have tested for in our interaction analysis.

Moreover, when we estimate the full quadratic equation we find that the restrictions (27) and (29) are again satisfied, and that the coefficients on the pure quadratic terms in

$\widehat{y}=y-y_{1}$ and $\widehat{F}=F-F^{1}$ are indeed not different from zero at conventional significance levels:

$$
g=\underset{(1.51)}{0.947}-\underset{(-5.05)}{4.122} \widehat{y}-\underset{(-1.42)}{0.022} \widehat{F}-\underset{(-1.45)}{0.000} \widehat{F}^{2}-\underset{(-2.53)}{0.031} \widehat{F} \widehat{y}-\underset{(-1.23)}{0.382} \widehat{y}^{2}
$$

(t-statistics in parentheses, sample size 71, OLS regression - dependent variable is average growth rate of per-capita GDP 1960-95). In this sense our estimated equation can be thought of as the second-order approximation (34) to our model without the insignificant pure quadratic terms.

\section{Appendix D: Sources and Description of Data}

setmortal: Log of European settler mortality, Acemoglu, Johnson and Robinson (2001). statehist: Measure of the antiquity of a state (1 to $1950 \mathrm{CE}$ ) regarding the existence of native foreign government and the extent of the territory ruled by this government. The measure used corresponds to statehist5 of the database in Bockstette, Chanda and Putterman (2002).

avgexpect: Average life expectancy at birth for the years 1960-1990, Children Data Bank for International.

socap: Measure of social capability deriving by Adelman and Morris (1967) using assessment of each country's development as of 1957-1962 in a variety of respects such as: extent of urbanization, extent of dualism, extent of social mobility, extent of literacy, crude fertility rate, degree of modernization of outlook, character of basic social organization, extent of mass communication, size of traditional agricultural sector and importance of indigenous middle class, Temple and Johnson (1998).

infra: Measure of social infrastructure (1986-1995) computed as the average of the GADP and an openness measures. GADP is an index of government antidiversion policies including law and order, bureaucratic quality, corruption, risk of expropriation and government repudiation of contracts, Hall and Jones (1999).

avgmort: Average under-5 mortality rate for the years 1970-1990, Children Data Bank for International.

pop100cr: Percentage of population within $100 \mathrm{~km}$ of ice-free coast, CID at Harvard University. General Measures of Geography.

tropop: Percentage of population in geographical tropics, CID at Harvard University. General Measures of Geography.

kkz: Composite index of six dimensions of governance: voice and accountability, political stability and absence of violence, government effectiveness, regulatory quality, rule of law, control of corruption, Kaufmann, Kraay and Zoido-Lobatón (1999).

me: Malaria Ecology. An ecologically-based variable that is predictive of the extent of malaria transmission (Kiszewski et al., forthcoming). Malaria is intrinsically a disease of warm environments because a key part of the life cycle of the parasite (sporogony) depends on a high ambient temperature. Malaria also depends on adequate conditions of mosquito 
breeding, mainly pools of clean water, usually due to rainfall ending up in puddles, cisterns, discarded tires, and the like. Additionally, the intensity of malaria transmission depends on the specific mosquito species that are present. The basic formula for Malaria Ecology combines temperature, mosquito abundance, and mosquito vector type. The underlying index is measured on a highly disaggregated sub-national level, and then averaged for the entire country and weighted by population, The Earth Institute at Columbia University.

bureau: An average of three indices published by Business International Corporation (1984): efficiency of the judiciary system, red tape and corruption. The averages are over the period 1980-1983.

exprisk: Expropriation risk. Assessment of risk of "outright confiscation" or "forced nationalization". It ranges from 0 to 10, with lower scores indicating a higher risk and data are averaged over 1982-1995, Knack and Keefer (1995).

lat_abst: Distance from the equator scaled between 0 and 1, La Porta, Lopez-de-Silanes, Shleifer and Vishny (1998) - henceforth LLSV (1998).

pr. rights: Property rights. Rating of property rights on a scale from 0 to 5 . The more protection private property receives, the higher the score, LLSV (1998).

soe: Index of state owned enterprises (SOE). Measures the role of SOEs in the economy, ranging from 0 to 10 . Higher scores denote countries with less government owned enterprises, which are estimated to produce less of the country's output, LLSV (1998).

corruption: Measure of corruption, with the scale readjusted from 0 (high level of corruption) to 10 (low level). Data are averaged over 1982-1995, Knack and Keefer (1995).

assass: Number of assassinations per 1000 inhabitants, averaged over 1960-1990, Banks (1994).

revc: Revolutions and coups. A revolution is defined as any illegal or forced change in the top of the governmental elite, any attempt at such a change, or any successful or unsuccessful armed rebellion whose aim is independence from central government. Coup d'Etat is defined as an extraconstitutional or forced change in the top of the governmental elite and/or its effective control of the nation's power structure in a given year. Unsuccessful coups are not counted. Data are averaged over 1960-1990, Banks (1994).

avelf: Ethnic fractionalization. Average value of five indices of ethnolinguistic fractionalization, with values ranging from 0 to 1 , where higher values denote higher levels of fractionalization, Easterly and Levine (1998).

rulelaw: Measure of the law and order tradition in a country. It is an average over 19821995. It ranges from 10, strong law and order tradition, to 1, weak law and order tradition, LLSV(1998).

bus. reg: Business regulation. Rating of regulation policies related to opening and keeping open a business. The scale is from 0 to 5 , with higher scores meaning that regulations are straightforward and applied uniformly to all businesses and that regulations are less of a burden to business, LLSV (1998).

civil: Index of civil liberties, Freedom House 1994.

legal origins: Dummy variables for British (Eng), French (Fre), German (Ger) and Scandinavian legal origins, LLSV (1998).

private credit: $\{(0.5) *[\mathrm{~F}(\mathrm{t}) / \mathrm{Pe}(\mathrm{t})+\mathrm{F}(\mathrm{t}-1) \mathrm{Pe}(\mathrm{t}-1)]\} /[\mathrm{GDP}(\mathrm{t}) / \mathrm{Pa}(\mathrm{t})]$, where $\mathrm{F}$ is credit by deposit money bank and other financial institutions to the private sectors (lines $22 \mathrm{~d}+$ 42d), GDP is line 99b, Pe is end- of period CPI (line 64) and Pa is the average CPI for the 
year, IFS.

bank assets: $\{(0.5) *[\mathrm{~F}(\mathrm{t}) / \mathrm{Pe}(\mathrm{t})+\mathrm{F}(\mathrm{t}-1) \mathrm{Pe}(\mathrm{t}-1)]\} /[\mathrm{GDP}(\mathrm{t}) / \mathrm{Pa}(\mathrm{t})]$, where $\mathrm{F}$ is domestic assets of deposit money banks (lines 22a-d), GDP is line 99b, Pe is end- of period CPI (line 64) and $\mathrm{Pa}$ is the average CPI for the year, IFS.

liquid liabilities: $\{(0.5) *[\mathrm{~F}(\mathrm{t}) / \mathrm{Pe}(\mathrm{t})+\mathrm{F}(\mathrm{t}-1) \mathrm{Pe}(\mathrm{t}-1)]\} /[\mathrm{GDP}(\mathrm{t}) / \mathrm{Pa}(\mathrm{t})]$, where $\mathrm{F}$ is liquid liabilities (line 55), GDP is line 99b, Pe is end- of period CPI (line 64) and Pa is the average CPI for the year, IFS.

commercial-central bank: $\mathrm{DBA}(\mathrm{t}) /(\mathrm{DBA}(\mathrm{t})+\mathrm{CBA}(\mathrm{t}))$, where $\mathrm{DBA}$ is assets of deposit money banks (lines 22a-d) and CBA is central bank assets (lines 12a-d), IFS.

bmp: Black market premium: Ratio of black market exchange rate and official exchange rate minus one, Picks' Currency Yearbook through (1989) and the World Currency Yearbook.

sec: Average years of secondary schooling in the population over 15 from 1960-1995, Barro and Lee (1996).

school: Average years of schooling in the population over 25 in 1960, Barro and Lee (1996). pi: Inflation rate. Log difference of consumer price index average from 1960-1995, IFS (line $64)$.

trade: Openness to trade. Sum of real exports and imports as a share of real GDP average 1960-1995, Levine, Loayza and Beck (2000), henceforth LLB.

gov: Government expenditure as a share of GDP average 1960-1995, LLB (2000).

africa: Dummy for countries in the African continent.

$\mathbf{y}_{-} \mathbf{y}_{1}$ : Difference between log per-capita real GDP 1960 in each country and the USA, LLB (2000).

gschool: Average annual growth rate of schooling from 1960 to 1995, LLB (2000).

hy: 1985 human-capital to output ratio, Klenow and Rodríguez-Clare (1997).

ghy: 1960-1985 annual growth rate of human capital to output ratio, Klenow and RodríguezClare (1997).

lna - lna 1 : The log of productivity in 1960 relative to the USA. For multi-factor productivity the data come from Benhabib and Spiegel (2002). For total-factor productivity we define the $\log$ of productivity as $1.5 \times[\log$ per-capita GDP - $(\log$ per-capita capital)/3] $0.7 \times$ (average years of schooling), using data from LLB (2000). 


\section{References}

Acemoglu, Daron, Philippe Aghion, and Fabrizio Zilibotti. "Distance to Frontier, Selection and Economic Growth." NBER Working Paper 9066 July, 2002.

Acemoglu, Daron, and Simon Johnson. "Unbundling Institutions." MIT mimeo, June 2003.

Acemoglu, Daron, Simon Johnson, and James A. Robinson. "The Colonial Origins of Comparative Development: An Empirical Investigation." American Economic Review 91 (December 2001): 1369-1401.

Acemoglu, Daron, and Fabrizio Zilibotti. "Productivity Differences." Quarterly Journal of Economics 116 (May 2001): 563-606.

Adelman, Irma, and Cynthia Taft Morris. Society, Politics and Economic Development: A Quantitative Approach. Baltimore: The Johns Hopkins University Press, 1967.

Aghion, Philippe, and Patrick Bolton. "A Model of Trickle-Down Growth and Development." Review of Economic Studies 64 (April 1997): 151-72.

Aghion, Philippe, Abhijit V. Banerjee, and Thomas Piketty. "Dualism and Macroeconomic Volatility." Quarterly Journal of Economics 114 (November 1999): 1359-97.

Aghion, Philippe, and Peter Howitt. Endogenous Growth Theory. Cambridge, MA: MIT Press, 1998.

Alfaro, Laura, Areendam Chanda, Sebnem Kalemli-Ozcan, and Selin Sayek. "FDI and Economic Growth: The Role of Local Financial Markets." Journal of International Economics (forthcoming 2003).

Arrow, Kenneth J. "Classificatory Notes on the Production and Transmission of Technological Knowledge." American Economic Review Papers and Proceedings 59 (May 1969): 29-35.

Banerjee, Abhijit, and Andrew Newman. "Occupational Choice and the Process of Development." Journal of Political Economy 101 (April 1993): 274-98.

Banerjee, Abhijit. "Contracting Constraints, Credit Markets and Economic Development." In Advances in Economics and Econometrics, edited by M. Dewatripont, L-P Hansen, and S. Turnovsky. Cambridge University Press, 2003.

Banks, Arthur S. "Cross-National Time Series Data Archive." Center for Social Analysis, University of New York at Binghampton 1994.

Barro, Robert J., and Jong Wha Lee. "International Measures of Schooling Years and Schooling Quality." American Economic Review 86 (May 1996): 218-24.

Barro, Robert J., and Xavier Sala-i-Martin. "Convergence." Journal of Political Economy 100 (April 1992): 223-51.

Barro, Robert J., and Xavier Sala-i-Martin. "Technological Diffusion, Convergence, and Growth." Journal of Economic Growth 2 (March 1997): 1-26.

Basu, Susanto, and David N. Weil. "Appropriate Technology and Growth." Quarterly Journal of Economics 113 (November 1998): 1025-54.

Bencivenga, Valerie R., and Bruce D. Smith. "Financial Intermediation and Endogenous Growth." Review of Economic Studies 58 (April 1991): 195- 210.

Bencivenga, Valerie R., and Bruce D. Smith. "Some Consequences of Credit Rationing in an Endogenous Growth Model." Journal of Economic Dynamics and Control 17 (January-March 1993): 97- 122. 
Benhabib, Jess, and Mark M. Spiegel. "Human Capital and Technology Diffusion." Produced for the forthcoming Handbook of Economic Growth, November 2002.

Bernanke, Ben, and Mark Gertler. "Agency Costs, Net Worth, and Business Fluctuations." American Economic Review 79 (March 1989): 14-31.

Blackburn, Keith, and Victor T. Y. Hung. "A Theory of Growth, Financial Development and Trade." Economica 65 (February 1998): 107-24.

Bockstette, Valerie, Areendam Chanda, and Louis Putterman. "States and Markets: The Advantage of an Early Start." Journal of Economic Growth 7 (December 2002): 347-69.

Business International Corporation. Introduction to the Country Assessment Service. New York: Business International Corporation, 1984.

Cohen, Wesley M., and Daniel A. Levinthal. "Innovation and Learning: The Two Faces of R\&D." Economic Journal 99 (September 1989): 569-96.

Davidson, Russell, and James G. MacKinnon. Estimation and Inference in Econometrics. New York: Oxford University Press, 1993.

De Gregorio, José. "Borrowing Constraints, Human Capital Accumulation, and Growth." Journal of Monetary Economics 37 (February 1996): 49-71.

Demirgüç-Kunt, Asli, and Ross Levine. Financial Structure and Economic Growth: A Cross-Country Comparison of Banks, Markets, and Development. Cambridge, MA: MIT Press, 2001.

Easterly, William, and Ross Levine. "Troubles with the Neighbours: Africa's Problems and Africa's Opportunities." Journal of African Economics 7 (March 1998): 120-42.

Easterly, William, and Ross Levine. "It's Not Factor Accumulation: Stylized Facts and Growth Models." World Bank Economic Review 15 (2001): 177- 219.

Evans, Paul. "Using Cross-Country Variances to Evaluate Growth Theories." Journal of Economic Dynamics and Control 20 (June-July 1996): 1027-49.

Evenson, Robert E., and Larry E. Westphal. "Technological Change and Technology Strategy." In Handbook of Development Economics, edited by T. N. Srinivasan and Jere Behrman, 2209-99. Handbooks in Economics, v.9. Vol. 3A. Amsterdam: Elsevier, 1995.

Feyrer, James. "Convergence by Parts." Unpublished, Brown University, March 2001.

de la Fuente, Angel, and José Maria Marin. "Innovation, Bank Monitoring, and Endogenous Financial Development." Journal of Monetary Economics 38 (October 1996): 269-301.

Galetovic, Alexander. "Specialization, Intermediation, and Growth." Journal of Monetary Economics 38 (December 1996): 549-59.

Galor, Oded, and Joseph Zeira. "Income Distribution and Macroeconomics." Review of Economic Studies 60 (January 1993): 35-52.

Gerschenkron, Alexander. "Economic Backwardness in Historical Perspective." In The Progress of Underdeveloped Areas, edited by Bert F. Hoselitz. Chicago: University of Chicago Press, 1952.

Greenwood, Jeremy, and Boyan Jovanovic. "Financial Development, Growth, and the Distribution of Income." Journal of Political Economy 98 (October 1990): 1076-1107.

Griffith, Rachel, Stephen Redding, and John Van Reenen. "Mapping the Two Faces of R\&D: Productivity Growth in a Panel of OECD Industries." unpublished, August 2001.

Grossman, Gene M., and Elhanan Helpman. Innovation and Growth in the Global Economy. Cambridge, MA: MIT Press, 1991. 
Hall, Robert E., and Charles I. Jones. "Why Do Some Countries Produce so Much More Output per Worker than Others?" Quarterly Journal of Economics 114 (February 1999): $83-116$.

Harrison, Paul, Oren Sussman, and Joseph Zeira. "Finance and Growth: Theory and New Evidence." Board of Governors of the Federal Reserve System, Finance and Economics Discussion Series 9935, July 1999.

Howitt, Peter. "Steady Endogenous Growth with Population and R\&D Inputs Growing." Journal of Political Economy 107 (August 1999): 715-30.

Howitt, Peter. "Endogenous Growth and Cross-Country Income Differences." American Economic Review 90 (September 2000): 829-46.

Howitt, Peter, and David Mayer-Foulkes. "R\&D, Implementation and Stagnation: A Schumpeterian Theory of Convergence Clubs." NBER Working Paper 9104, August 2002 .

Jones, Charles I. "R\&D-Based Models of Economic Growth." Journal of Political Economy 103 (August 1995): 759-84.

Kahn, Aubhik. "Financial Development and Economic Growth." Macroeconomic Dynamics 5 (2001): 413-33.

Kaufmann, D., A. Kraay, and P. Zoido-Lobatón. "Aggregating Governance Indicators." World Bank Research Working Paper No. 2195, 1999a.

Kaufmann, D., A. Kraay, and P. Zoido-Lobatón. "Governance Matters." World Bank Research Working Paper No. 2196, 1999 b.

Keller, Wolfgang. "Technology Diffusion and the World Distribution of Income: The Role of Geography, Language, and Trade." Unpublished, University of Texas, June 2002.

King, Robert G., and Ross Levine. "Finance, Entrepreneurship, and Growth." Journal of Monetary Economics 32 (December 1993): 513-42.

Kiszewski, Anthony, Andrew Mellinger, Pia Malaney, Andrew Spielman, Sonia Ehrlich, and Jeffrey D. Sachs. "A Global Index of the Stability of Malaria Transmission Based on the Intrinsic Properties of Anopheline Mosquito Vectors." American Journal of Tropical Medicine and Hygiene (forthcoming, 2003).

Klenow, Peter J., and Andrés Rodríguez-Clare. "The Neoclassical Revival in Growth Economics: Has it Gone too Far?" In NBER Macroeconomics Annual, edited by Ben Bernanke and Julio Rotemberg, 73-103. Cambridge, MA: MIT Press, 1997.

Knack, Stephen, and Philip Keefer. "Institutions and Economic Performance: CrossCountry Tests Using Alternative Institutional Measures." Economics and Politics 7 (November 1995): 207-27.

Krebs, Tom. "Human Capital Risk and Economic Growth." Quarterly Journal of Economics 118 (May 2003): 709-44.

La Porta, Rafael, Florencio Lopez-de-Silanes, Andrei Shleifer, and Robert W. Vishny. "Legal Determinants of External Finance." Journal of Finance 52 (1997): 1131-50.

La Porta, Rafael, Florencio Lopez-de-Silanes, Andrei Shleifer, and Robert W. Vishny. "Law and Finance." Journal of Political Economy 106 (December 1998): 1113-55.

Levine, Ross. "Stock Markets, Growth, and Tax Policy." Journal of Finance 46 (September 1991): $1445-65$.

Levine, Ross. "Financial Development and Economic Growth: Views and Agenda." Journal of Economic Literature 35 (June 1997): 688-726. 
Levine, Ross. "Finance and Growth: Theory, Evidence, and Mechanisms." Produced for the forthcoming Handbook of Economic Growth, March 18, 2003.

Levine, Ross, Norman Loayza, and Thorsten Beck. "Financial Intermediation and Growth: Causality and Causes." Journal of Monetary Economics 46 (August 2000): 31-77.

Lucas, Robert E. Jr. "On the Mechanics of Economic Development." Journal of Monetary Economics 22 (January 1988): 3-42.

Maddison, Angus. The World Economy: A Millennial Perspective. Development Centre Studies. Paris: OECD, 2001.

Mankiw, N. Gregory, David Romer, and David N. Weil. "A Contribution to the Empirics of Economic Growth." Quarterly Journal of Economics 107 (May 1992): 407-37.

Mayer-Foulkes, David. "Global Divergence." Documento de Trabajo del CIDE, SDTE 250, División de Economía, 2002.

Morales, María F. "Financial Intermediation in a Model of Growth Through Creative Destruction." Macroeconomic Dynamics 7 (June 2003): 363-93.

Nelson, Richard, and Edmund S. Phelps. "Investment in Humans, Technological Diffusion, and Economic Growth." American Economic Review 56 (March 1966): 69-75.

Parente, Stephen L., and Edward C. Prescott. "Technology Adoption and Growth." Journal of Political Economy 102 (April 1994): 298-321.

Parente, Stephen L., and Edward C. Prescott. "Monopoly Rights: A Barrier to Riches." American Economic Review 89 (December 1999): 1216-33.

Piketty, Thomas. "The Dynamics of the Wealth Distribution and the Interest Rate with Credit Rationing", Review of Economic Studies 64 (April 1997): 173-89.

Pritchett, Lant. "Divergence, Big-Time." Journal of Economic Perspectives 11 (Summer 1997): 3-17.

Pritchett, Lant. "The Tyranny of Concepts: Cumulative, Depreciated Investment Effort (CUDIE) is not Investment." Journal of Economic Growth 5 (December 2000): 361-84.

Rajan, Raghuram G., and Luigi Zingales. "Financial Dependence and Growth." American Economic Review 88 (June 1998): 559-86.

Rioja, Felix, and Neven Valev. "Finance and the Sources of Growth at Various Stages of Economic Development." Economic Inquiry (forthcoming 2003).

Sachs, Jeffrey D. "Institutions Don't Rule: Direct Effects of Geography on Per Capita Income." NBER Working paper 9490, February 2003.

Saint-Paul, Gilles. "Technology Choice, Financial Markets and Economic Development." European Economic Review 36 (May 1992): 763-81.

Sussman, Oren. "A Theory of Financial Development." In Finance and Development: Issues and Experience, edited by A. Giovannini, 29-64. Cambridge, UK: Cambridge University Press, 1993.

Temple, Jonathan, and Paul A. Johnson. "Social Capability and Economic Growth." Quarterly Journal of Economics 113 (August 1998): 965-90. 